\title{
Use of Cool Roofs and Vegetation to Mitigate Urban Heat and Improve Human Thermal Stress in Melbourne, Australia ${ }^{\mathscr{O}}$
}

\author{
Stephanie J. Jacobs And Ailie J. E. Gallant \\ School of Earth, Atmosphere and Environment, and Cooperative Research Centre for Water Sensitive Cities, \\ and Australian Research Council Centre of Excellence for Climate System Science, Monash University, \\ Melbourne, Victoria, Australia \\ NiGEL J. TAPPER \\ School of Earth, Atmosphere and Environment, and Cooperative Research Centre for Water Sensitive Cities, \\ Monash University, Melbourne, Victoria, Australia \\ DAN LI \\ Department of Earth and Environment, Boston University, Boston, Massachusetts
}

(Manuscript received 22 August 2017, in final form 12 May 2018)

\begin{abstract}
The ability of cool roofs and vegetation to reduce urban temperatures and improve human thermal stress during heat wave conditions is investigated for the city of Melbourne, Australia. The Weather Research and Forecasting Model coupled to the Princeton Urban Canopy Model is employed to simulate 11 scenarios of cool roof uptake across the city, increased vegetation cover across the city, and a combination of these strategies. Cool roofs reduce urban temperatures during the day, and, if they are installed across enough rooftops, their cooling effect extends to the night. In contrast, increasing vegetation coverage reduces nighttime temperatures but results in minimal cooling during the hottest part of the day. The combination of cool roofs and increased vegetation scenarios creates the largest reduction in temperature throughout the heat wave, although the relationship between the combination scenarios is nonsynergistic. This means that the cooling occurring from the combination of both strategies is either larger or smaller than if the cooling from individual strategies were to be added together. The drier, lower-density western suburbs of Melbourne showed a greater cooling response to increased vegetation without enhancing human thermal stress due to the corresponding increase in humidity. The leafy medium-density eastern suburbs of Melbourne showed a greater cooling response to the installation of cool roofs. These results highlight that the optimal urban cooling strategies can be different across a single urban center.
\end{abstract}

\section{Introduction}

Heat waves, known as the "silent killer," have caused more fatalities in Australia than tropical cyclones, bushfires, earthquakes, and floods combined (Hughes et al. 2016). A heat wave can be defined as three or more days of extremely high temperatures, often with no relief at night (Perkins and Alexander 2013). If people are exposed to heat waves, heat

Supplemental information related to this paper is available at the Journals Online website: https://doi.org/10.1175/JAMC-D-170243.s1.

Corresponding author: stephanie.jacobs@monash.edu stroke and hyperthermia can sometimes occur, resulting in death. During heat waves, excess deaths and ambulance callouts are often significantly higher for unusually warm minimum temperatures than for maximum temperatures, as health problems occur when people cannot cool down at night (Williams et al. 2012). To predict the effects of heat waves on human health, a human thermal stress index is often used (Goldie et al. 2017). This is because factors such as temperature, solar radiation, wind, and humidity can often alter the human body thermoregulation and thus how much stress a person can feel (Anderson et al. 2013).

There is a greater risk of heat stress in cities than in adjacent rural areas because of the urban heat island 
effect (UHI; Fischer et al. 2012). Cities can be hotter than their surrounding areas, especially at night, for a range of reasons, including building materials with large heat capacity; building geometry that facilitates radiative trapping; multiple anthropogenic heat sources such as people, cars, and air conditioners; and a lack of vegetation (Oke 1987). In Melbourne, Australia, $75 \%$ of the days between 1973 and 1991 exhibit a UHI between $0^{\circ}$ and $2^{\circ} \mathrm{C}$ and the UHI has been recorded as high as $6^{\circ} \mathrm{C}$, albeit not during heat wave conditions (Morris and Simmonds 2000). Heat waves have been shown to sometimes have a synergistic effect on the UHI in cities around the world where the magnitude of the UHI grows during heat waves ( $\mathrm{Li}$ and Bou-Zeid 2013; Li et al. 2015; Heaviside et al. 2015). Therefore, investigating techniques to reduce urban heat is imperative for improving human thermal stress.

Increasing the albedo of surface areas in cities has been shown to be one effective method of mitigating urban heat (Gago et al. 2013). Changing the albedo of rooftops is seen as a straightforward strategy to implement as rooftops constitute an estimated $20 \%$ of urban surfaces around the world (Akbari et al. 2009; Zinzi and Agnoli 2012). Cool roofs - in which a roof is either painted white or is made of highly reflective material or a colored roof is covered in highly reflective paint-are seen as an urban heat-mitigation option (Santamouris 2014). They reflect incoming solar radiation more efficiently than darker roofs, reducing the amount of heat that is absorbed by the rooftop and the building itself and ultimately transferred to the atmosphere (Kalkstein et al. 2013). This was demonstrated in an observational study of cool roofs in Melbourne in which the net radiation at midday was $78 \%$ lower than for a vegetated rooftop during summer (Coutts et al. 2013). Modeling studies from New York City, New York, and Athens, Greece, have shown that for every 0.1 increase in roof albedo the corresponding change in maximum and minimum temperature is $-0.41^{\circ}$ and $-0.02^{\circ} \mathrm{C}$, respectively (Santamouris 2014). For the Baltimore, Maryland-Washington, D.C., area, as the fraction of cool roofs increases the near-surface UHI decreases almost linearly ( $\mathrm{Li}$ et al. 2014). Moreover, increasing the urban albedo by $20 \%$ in Phoenix, Arizona, has been shown to potentially reduce heat-related emergency calls by over 150 incidences per year (Silva et al. 2010). However, factors such as the weather conditions, climate, and geography of a city can reduce the effectiveness of high-albedo surfaces in cities, suggesting that different cities require different solutions to the UHI (Yang et al. 2015b).

Increasing the proportion of parks and green spaces in urban areas is another method to cool cities, where parks can be up to $4^{\circ} \mathrm{C}$ cooler than surrounding urban areas (Eliasson 1996), albeit this can depend on the vegetation type, the park size, and the climate of the city (Gago et al. 2013; Bowler et al. 2010). Parks can reduce the cooling loads of neighboring buildings (Chen and Wong 2006) and the cooling effect from large parks has been shown to extend up to $1 \mathrm{~km}$ beyond the park boundary (Upmanis et al. 1998). A modeling study of Singapore found that if vegetation in the commercial district was increased from $5 \%$ to $50 \%$ then nighttime temperatures would decrease by up to $2^{\circ} \mathrm{C}(\mathrm{Li}$ and Norford 2016).

In January of 2009, the city of Melbourne experienced a record-breaking heat wave consisting of three days above $43^{\circ} \mathrm{C}$ and one night above $30^{\circ} \mathrm{C}$ (Jacobs et al. 2017). A total of 374 excess deaths and 714 hospital admissions were attributed to this heat wave (Victorian Department of Health 2009). Another heat wave in January of 2014 caused 167 excess deaths (Department of Health 2014). Melbourne has a population close to five million people, which is projected to increase to eight million residents by 2050 (Department of Environment Land Water and Planning 2017). This could potentially increase the urban heat island in a climate that is also likely to increasingly experience hotter, longer, and more frequent heat waves (Cowan et al. 2014). This drives the need to investigate urban adaptation technologies to counteract deadly heat waves. Moreover, as different regions of Melbourne are vulnerable to heat stress because of local climate and socioeconomic demographics (Loughnan et al. 2013), understanding which regions best respond to different types of heat-mitigation strategies allows targeted and more efficient schemes to be implemented.

In this study, we model the near-surface air temperature and apparent temperature response to the implementation of cool roofs and increased vegetation across Melbourne under heat wave conditions. We discuss the mechanisms involved in the changes to temperature and apparent temperature and also investigate how responsive Melbourne is to a combination of mitigation strategies.

\section{Data and methods}

\section{a. WRF Model setup}

We use the Weather Research Forecasting (WRF) Model, version 3.6.0 (Skamarock et al. 2008), to simulate an ensemble of 12 heat wave scenarios and two mitigation measures (cool roofs and urban greening) for Melbourne. WRF is a nonhydrostatic mesoscale model that has been widely used to simulate heat waves (Kala et al. 2015; Jacobs et al. 2017) and cities for the current and future climate (Argüeso et al. 2014; Kohler et al. 2017; 
Wu et al. 2014). WRF is also used to model the UHI (Ma et al. 2017; Chen et al. 2014), urban heat mitigation (Ma et al. 2018; Li et al. 2014; Li and Norford 2016), and future urban heat stress (Argüeso et al. 2015).

The WRF physics schemes allow the model to parameterize various processes that cannot be fully represented in the model simulations. The physics schemes used are the Kain-Fritsch cumulus scheme (Kain 2004), the Dudhia shortwave radiation scheme (Dudhia 1989), the eta surface layer similarity scheme (Janjić 1994), the Rapid Radiative Transfer Model longwave radiation scheme (Mlawer et al. 1997), the WRF double-moment five-class scheme (Lim and Hong 2010), the MellorYamada-Janjić planetary boundary layer scheme (Janjić 1994) and the Noah land surface model (LSM; Tewari et al. 2004). This combination of physics schemes is one of the best for modeling southeastern Australia on multiday time scales (Evans et al. 2012).

The urban areas of Melbourne are modeled using the Princeton Urban Canopy Model (PUCM; Wang et al. 2013), coupled to WRF. The PUCM is based on the default WRF Single-Layer Urban Canopy Model (SLUCM) energy exchange framework (Kusaka et al. 2001; Chen et al. 2011). It simulates the energy balances/momentum and energy fluxes of the three main urban facets of the roof, wall, and ground, and the Noah LSM simulates the energy budget/momentum and energy fluxes of the vegetated pervious fraction. The PUCM and Noah LSM impervious and pervious surface outputs variables, such as the surface heat fluxes and surface temperature, that are then combined and weighted for the WRF grid cell based on the urban fraction (FRC_URB) defined in the PUCM parameter table (URBPARM.TBL). Anthropogenic heat is not considered in this study. For more details on the WRF and PUCM setup, including validation, see Wang et al. (2013), Li and Bou-Zeid (2014), Li et al. (2014), and Ramamurthy et al. (2017).

The advantage of using the PUCM-coupled WRF is that it is able to differentiate the ground surface into urban grass, concrete, and asphalt and the roof into a combination of cool roofs and conventional roofs $(\mathrm{Li}$ and Bou-Zeid 2014; Wang et al. 2013). The ability to simulate a fraction of cool roofs is not available in SLUCM, where only one roof albedo can be defined. Our research further benefits from using PUCM coupled to WRF because a percentage of cool roofs offers a more realistic mitigation strategy simulation, rather than a best-case scenario of the $100 \%$ uptake of cool roofs across a city (e.g., Georgescu et al. 2014; Ma et al. 2018; Li and Norford 2016). This is the first time that the WRF and PUCM setup has been used to research an Australian city.
The PUCM also has detailed hydrologic models included, many of which were introduced into newer editions of the WRF urban model (Yang et al. 2015a; Ramamurthy et al. 2017). However, cool roof capabilities, which have been shown to be effective in reducing building heat loadings in a dry summer climate such as Melbourne (Coutts et al. 2013), were not included in the model update.

The WRF simulations are driven by $0.7^{\circ} \times 0.7^{\circ}$ gridded ERA-Interim reanalysis data (Dee et al. 2011). These are downscaled over two domains, the larger at $10-\mathrm{km}$ resolution covering southeast Australia, the smaller at a convection-permitting 2-km resolution centered on Melbourne and its surrounding regions (Fig. 1a). The Kain-Fritsch cumulus scheme is only used for the largest domain because convection can be resolved in WRF with a 2-km domain resolution; hence the cumulus scheme is unnecessary for domain 2 . To define vegetation categories, the MODIS land surface categories are applied (Fig. 1b). MODIS only has one urban land surface category, yet the PUCM can simulate up to three urban categories. For our analysis the three default urban categories of low density, high density, and commercial/industrial are replaced with low-density, medium-density, and high-density urban. This is because Melbourne has few high-density areas so using the default categories would cause a loss of heterogeneity. The spatial representation of these categories for Melbourne is defined by Jackson et al. (2010) with the commercial/industrial category combined with the high-density urban categories and incorporated into the WRF preprocessing files as in Jacobs et al. (2017). This resulted in domain 2 containing 9 high-density, 256 medium-density, and 454 low-density points of 30000 total. There is a greater level of uncertainty related to the high-density urban grid points because there are so few relative to the other urban types.

The default urban parameters in WRF can significantly affect the accuracy of simulations over cities and must be set for each city (Wang et al. 2011; Barlage et al. 2016). These are adjusted using observations for Melbourne from Coutts et al. (2007). The urban fraction in WRF, defined as the fraction of urban surface that is not vegetation, is set at $0.71,0.77$, and 0.8 for low-, medium-, and high-density urban fractions, respectively. The roof heights are altered to $7.2,6.4$, and $8.8 \mathrm{~m}$, and the control roof albedo is changed to $0.17,0.15$, and 0.19 for low-, medium-, and high-density urban, respectively (Coutts et al. 2007).

ERA-Interim has an average soil moisture bias of $+0.1 \mathrm{~m}^{3} \mathrm{~m}^{-3}$ for Australian soils (Albergel et al. 2013), which was found to be too moist for accurate heat wave simulations of Melbourne and its surrounding regions 
(a)

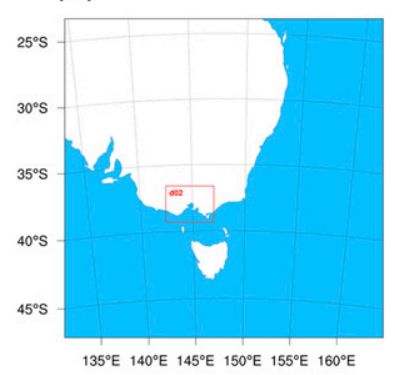

(b)

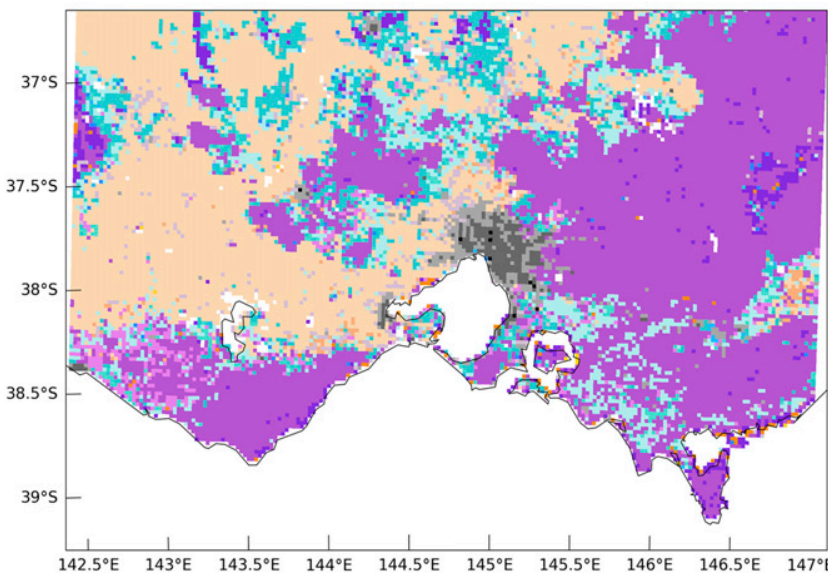

High Density Urban Medium Density Urban Low Density Urban Water Barren or Sparsely Vegetated Cropland/Natural Vegetation Mosaic Croplands Permanent Wetlands Grasslands Savannas Woody Savannas Open Shrublands Closed Shrublands Mixed Forests Deciduous Broadleaf Forest Evergreen Broadleaf Forest Evergreen Needleleaf Forest

FIG. 1. (a) The two WRF modeling domains used for analysis, and (b) the MODIS land use categories defined for domain 2 with Melbourne at the center of the domain [d02; red box in (a)]. Regions of high-, medium-, and low-density urban in domain 2 are defined by Jackson et al. (2010).

(Jacobs et al. 2017). To improve the WRF heat wave simulation accuracy for this research, the top layer of ERA-Interim reanalysis soil moisture is replaced with the upper-layer soil moisture from the Australian Water Availability Project (AWAP; Raupach et al. 2009). The AWAP soil moisture is a high-resolution reanalysis product that is based on observed temperature, precipitation, and solar irradiance, combined with remotely sensed land surface temperatures and vegetation greenness products. For further information, see Raupach et al. (2009) and Jacobs et al. (2017).

The top layer of AWAP soil moistures is an order of magnitude drier than the ERA-Interim soil moistures and much more representative of the southeast Australian climate (Jacobs et al. 2017). Adding AWAP soil moistures to the simulation of a heat wave over Melbourne reduces the surface and near-surface temperature bias by up to $0.8^{\circ}$ and $1^{\circ} \mathrm{C}$ respectively, whereas the atmospheric vapor pressure bias decreases by up to $0.7 \mathrm{hPa}$ (Jacobs et al. 2017).

\section{b. Defining heat waves}

To define a summer (December, January, and February) heat wave event in Melbourne, daily maximum and minimum temperatures for the Melbourne Regional Office weather station are obtained from the Australian Climate Observations Reference NetworkSurface Air Temperature (ACORN-SAT) database (Trewin 2013). ACORN-SAT is a newly developed high-quality homogenized dataset for Australian weather stations dating from 1910 to present. Heat waves are defined as periods of three or more days on which the maximum temperature exceeds the 90th percentile for each historical day of the heat wave and the minimum temperature on the second or third day of the heat wave exceeds the 90th percentile for that historical day (Pezza et al. 2012). The percentile base period was 1910-2014.

For the robust simulation of heat wave conditions in Melbourne, an ensemble of 12 heat waves over the period 1990-2014 were selected for analysis (Table 1). The 12 heat waves created an ensemble of 39 heat wave days. Each heat wave simulation is given a $37-\mathrm{h}$ spinup time with midnight on the first day of the heat wave used as the first time step for analysis. For example, the 2009 heat wave simulation from 28 to 30 January began at 1100 local time (LT) 26 January and finished at midnight 30 January.

\section{c. Urban heat-mitigation scenarios}

We simulate three groups of scenarios: a control scenario, the implementation of cool roofs across the city, and

TABLE 1 . List of the 12 summer heat waves chosen for analysis.

\begin{tabular}{llc}
\hline \hline Year & \multicolumn{1}{c}{ Date } & $\begin{array}{c}\text { Highest max temperature } \\
\text { of heat wave }\left({ }^{\circ} \mathrm{C}\right)\end{array}$ \\
\hline 1990 & 4-7 Dec & 36.9 \\
1993 & 1-3 Feb & 41.3 \\
1994 & 4-7 Dec & 39.1 \\
1997 & 19-21 Jan & 41.2 \\
1997 & 18-20 Feb & 40.8 \\
1998 & 10-12 Dec & 41.9 \\
1999 & 30 Nov-2 Dec & 37.2 \\
2006 & 20-22 Jan & 42.4 \\
2007 & 4-6 Jan & 36.6 \\
2009 & 28-30 Jan & 45.1 \\
2013 & 16-18 Feb & 36.7 \\
2014 & 14-17 Jan & 43.9 \\
\hline
\end{tabular}


an increase of the vegetation cover. The control scenario is the most realistic representation of Melbourne during heat wave conditions using observational urban fractions and roof albedos defined in section 2a. The control simulation has $100 \%$ conventional roofs. The control scenario is validated against observations in section 3 and used to compare with the cool roof and increased vegetation scenarios.

Two cool roof scenarios were implemented where $30 \%$ of the urban rooftops were classified as cool roofs (CR30) and $60 \%$ of the urban rooftops were classified as cool roofs (CR60), with the remaining roofs classified as conventional. The PUCM is a spatially averaged model meaning that there is no distinction between individual buildings. Therefore, the fraction of buildings with cool roofs can either be viewed as $60 \%$ of the buildings in the urban grid cell have cool roofs while the rest have conventional roofs, or that each building has a rooftop that is $60 \%$ cool roof and $40 \%$ conventional roof ( $\mathrm{Li}$ et al. 2014). The cool roof albedo is given as 0.7 ( $\mathrm{Li}$ et al. 2014), which represents a new cool roof. However, the albedo of cool roofs can decrease over time because of the accumulation of dirt ( $\mathrm{Li}$ et al. 2014). Nevertheless, these scenarios represent more-realistic implementation targets than the often simulated $100 \%$ cool roof scenarios (e.g., Georgescu et al. 2014; Ma et al. 2018; Li and Norford 2016).

An increase of vegetation cover in WRF was simulated by reducing the urban fraction defined in the PUCM parameter table. This represents an increase in the pervious proportion of an urban grid cell where the vegetation is a mix of bare soil, croplands, forests, shrublands, and grasslands (Strahler et al. 1999). Using the AWAP soil moisture in the WRF preprocessing files results in a spatially averaged top $(<10 \mathrm{~cm})$ and second layer $(10-40 \mathrm{~cm})$ soil moisture fraction at midnight on the first heat wave day of 0.06 and 0.18 , respectively. This indicates that the top layer is very close to wilting point, whereas the second layer is at $25 \%$ of its field capacity. As a result, shallow vegetation has limited access to water as compared with vegetation with roots that extend past $10 \mathrm{~cm}$.

The three increased vegetation scenarios are shown in Table 2 where the vegetation fraction is increased by $5 \%$ (VEG5) and 10\% (VEG10) relative to the control values for low-, medium-, and high-density urban points, and where the vegetation fraction is equal to $40 \%$ (VEG40) across all urban densities. This more ambitious vegetation fraction of $40 \%$ is based on a report by the City of Melbourne (encompassing the central business district of Melbourne) aiming to have $40 \%$ tree canopy cover in Melbourne by 2040 (City of Melbourne Council 2013).
TABLE 2. Urban fraction for the control and increased vegetation mitigation scenarios.

\begin{tabular}{lccc}
\hline \hline Scenario & $\begin{array}{c}\text { Urban fraction } \\
\text { for low density }\end{array}$ & $\begin{array}{c}\text { Urban fraction } \\
\text { for medium density }\end{array}$ & $\begin{array}{c}\text { Urban fraction } \\
\text { for high density }\end{array}$ \\
\hline Control & $71 \%$ & $77 \%$ & $80 \%$ \\
VEG5 & $67 \%$ & $73 \%$ & $76 \%$ \\
VEG10 & $64 \%$ & $69 \%$ & $72 \%$ \\
VEG40 & $60 \%$ & $60 \%$ & $60 \%$ \\
\hline
\end{tabular}

We also model a combination of the cool roof and increased vegetation mitigation scenarios to determine their effects on urban temperature and human thermal stress. Modeling two strategies at the same time is not as common in the literature, despite a varied approach to urban heat mitigation often being recommended (e.g., Coutts et al. 2013). This analysis allows us to test whether there are interactions between different mitigation scenarios, and can help determine policy outcome if a specific combination is a particularly efficient heat mitigator.

By analyzing urban heat mitigation on a climatology of 12 heat waves we are able to show the mean temperature response to the scenarios as opposed to the more common singular event or seasonal analysis in the literature (e.g., Li et al. 2014; $\mathrm{Ma}$ et al. 2018; Li and Norford 2016). Moreover, we are able to provide some measure of inter-heat wave variability.

\section{d. Defining human thermal stress}

While we are interested in the sensitivity of nearsurface temperatures to the urban heat-mitigation strategies, we are also interested in how these strategies affect human thermal stress. We use the apparent temperature (AT) (Steadman 1994) as our measure of human thermal stress:

$$
\mathrm{AT}=T+0.33 e-0.70 U-4.00 .
$$

The AT $\left({ }^{\circ} \mathrm{C}\right)$ is the current human thermal stress index used by the Australian Bureau of Meteorology, where $T$ is the air temperature $\left({ }^{\circ} \mathrm{C}\right), e$ is the vapor pressure $(\mathrm{hPa})$, and $U$ is the $2-\mathrm{m}$ wind speed $\left(\mathrm{m} \mathrm{s}^{-1}\right)$. The AT assumes that a human is walking at $0.5 \mathrm{~m} \mathrm{~s}^{-1}$ in a shady area. Because of the formulation of the AT, the temperature is the crucial variable, meaning that the AT could vary quasi-linearly to a temperature over- or underestimation. The AT has previously been used to define heat stress in Melbourne during extreme events (Jacobs et al. 2014, 2015).

The vapor pressure was defined using the 2-m dewpoint temperature $T_{d}\left({ }^{\circ} \mathrm{C}\right)$ :

$$
e=6.11 \times 10^{\left(\frac{7.5 \times T_{d}}{273.3+T_{d}}\right)},
$$


and the $10-\mathrm{m}$ wind speed output was converted to $2 \mathrm{~m}$ using the logarithmic wind equation from Bröde et al. (2012):

$$
U_{2 \mathrm{~m}}=U_{10 \mathrm{~m}} \times \frac{\ln (2 / 0.01)}{\ln (10 / 0.01)}
$$

Other measures of human thermal stress, such as the universal thermal climate index (UTCI; Bröde et al. 2012), are not appropriate when modeling on a $2 \mathrm{~km} \times$ $2 \mathrm{~km}$ grid scale, since the UTCI relies heavily on the mean radiant temperature. The mean radiant temperature is a value that combines all shortwave and longwave radiation (Gosling et al. 2014) and varies considerably over distances on the order of meters because it is dependent on the sky-view factor.

\section{Results}

\section{a. Model validation}

To validate the WRF heat wave simulations against observations for Melbourne, we used the AWAP maximum and minimum temperature and 0900 and $1500 \mathrm{LT}$ vapor pressure available on a $0.05^{\circ} \times 0.05^{\circ}$ grid (Jones et al. 2009). To directly compare the gridded WRF simulations with the observations, we regridded the 2-km-resolution WRF domain-2 data (Fig. 1b) to the $\sim 5$-km AWAP grid using a nearest-neighbor method. The WRF 2-m temperature at 1500 and 0300 were considered closest to the maximum and minimum temperature, respectively, and used for the comparison. To validate the WRF simulations for urban areas we created a mask to highlight all urban grid points within domain 2 for the 39 heat wave days and then took a spatial average of the data. The same mask was applied to the AWAP data so that only data in urban areas were used.

The WRF near-surface maximum temperature underestimates the observed maximum temperature by $1.9^{\circ} \mathrm{C}$ and overestimates the near-surface minimum temperature by $1.1^{\circ} \mathrm{C}$ (Table 3 ). Such biases are a common feature of WRF simulations where the diurnal temperature range is often underestimated (e.g., Argüeso et al. 2014; Miao et al. 2007; Giannaros et al. 2013). The observed maximum temperature regularly exceeds $40^{\circ} \mathrm{C}$ during heat waves in Melbourne (Table 1), so while biases exist, an underestimation of less than $2^{\circ} \mathrm{C}$ is acceptable as the heat waves would still be considered severe.

At 0900 and 1500 LT, WRF overestimates the mean response near-surface urban vapor pressure by 0.4 and $1.2 \mathrm{hPa}$, respectively (Table 3 ). Despite the addition of the drier AWAP soil moisture data, WRF still cannot
TABLE 3. The mean bias between the gridded AWAP temperature and vapor pressure or wind speed observations from Melbourne Airport and Laverton and the WRF control heat wave simulations. The gridded mean bias was spatially averaged over urban grid points in domain 2 over the 39 heat wave days.

\begin{tabular}{lc}
\hline \multicolumn{1}{c}{ Variable } & Mean model bias \\
\hline Max temperature & $-1.9^{\circ} \mathrm{C}$ \\
Min temperature & $1.1^{\circ} \mathrm{C}$ \\
0900 vapor pressure & $0.4 \mathrm{hPa}$ \\
1500 vapor pressure & $1.2 \mathrm{hPa}$ \\
Melbourne Airport $10-\mathrm{m}$ wind speed & $-0.9 \mathrm{~m} \mathrm{~s}^{-1}$ \\
Laverton 10-m wind speed & $0.1 \mathrm{~m} \mathrm{~s}^{-1}$ \\
\hline
\end{tabular}

fully replicate the extremely hot and dry conditions that occur during heat waves in Melbourne. Imran et al. (2018) found that when modeling heat waves in Melbourne using WRF with the SLUCM forced by ERA-Interim data, the simulations underestimated the maximum temperature by $2^{\circ}-5^{\circ} \mathrm{C}$. This indicates that using the AWAP soil moisture in the WRF initial conditions helps to improve the accuracy of heat wave simulations in Melbourne as was also shown in Jacobs et al. (2017) using AWAP and the SLUCM. The model performance for the near-surface temperature and vapor pressure is acceptable for use with urban heatmitigation scenarios as the WRF simulations produced heat wave conditions in Melbourne. The underestimation of temperature and overestimation of vapor pressure does not greatly affect the apparent temperature as these differences counteract each other.

The WRF 10-m wind speed is also validated against observations. Weather station data from the Australian Bureau of Meteorology is used as gridded wind speed datasets such as ERA-Interim are too coarse for comparison with WRF. Only two weather stations in Melbourne have wind measurements covering the analysis period of $1990-2014$, Melbourne Airport $\left(37.7^{\circ} \mathrm{S}\right.$, $\left.144.8^{\circ} \mathrm{E}\right)$ and Laverton $\left(37.9^{\circ} \mathrm{S}, 144.8^{\circ} \mathrm{E}\right)$. The $10-\mathrm{m}$ wind speed of the closest WRF grid point to these stations is used for validation, with each WRF grid point representing low-density urban. Note, however, that weather station wind speeds can be flawed, particularly in urban areas as the surroundings can have a profound effect on the measurements (Troccoli et al. 2012). Moreover, comparing one point with a 2-km grid average is a stern test of the model. Nevertheless, the mean bias between the observational $10-\mathrm{m}$ wind speed and WRF shows that for Melbourne Airport WRF underestimates the average heat wave wind speed by $0.9 \mathrm{~m} \mathrm{~s}^{-1}$ and overestimates the wind speed at Laverton by $0.1 \mathrm{~m} \mathrm{~s}^{-1}$ (Table 3 ). Wind speed biases in WRF often have a complex pattern depending on the case study and physics parameterization schemes used (Evans et al. 2012). The Melbourne Airport 

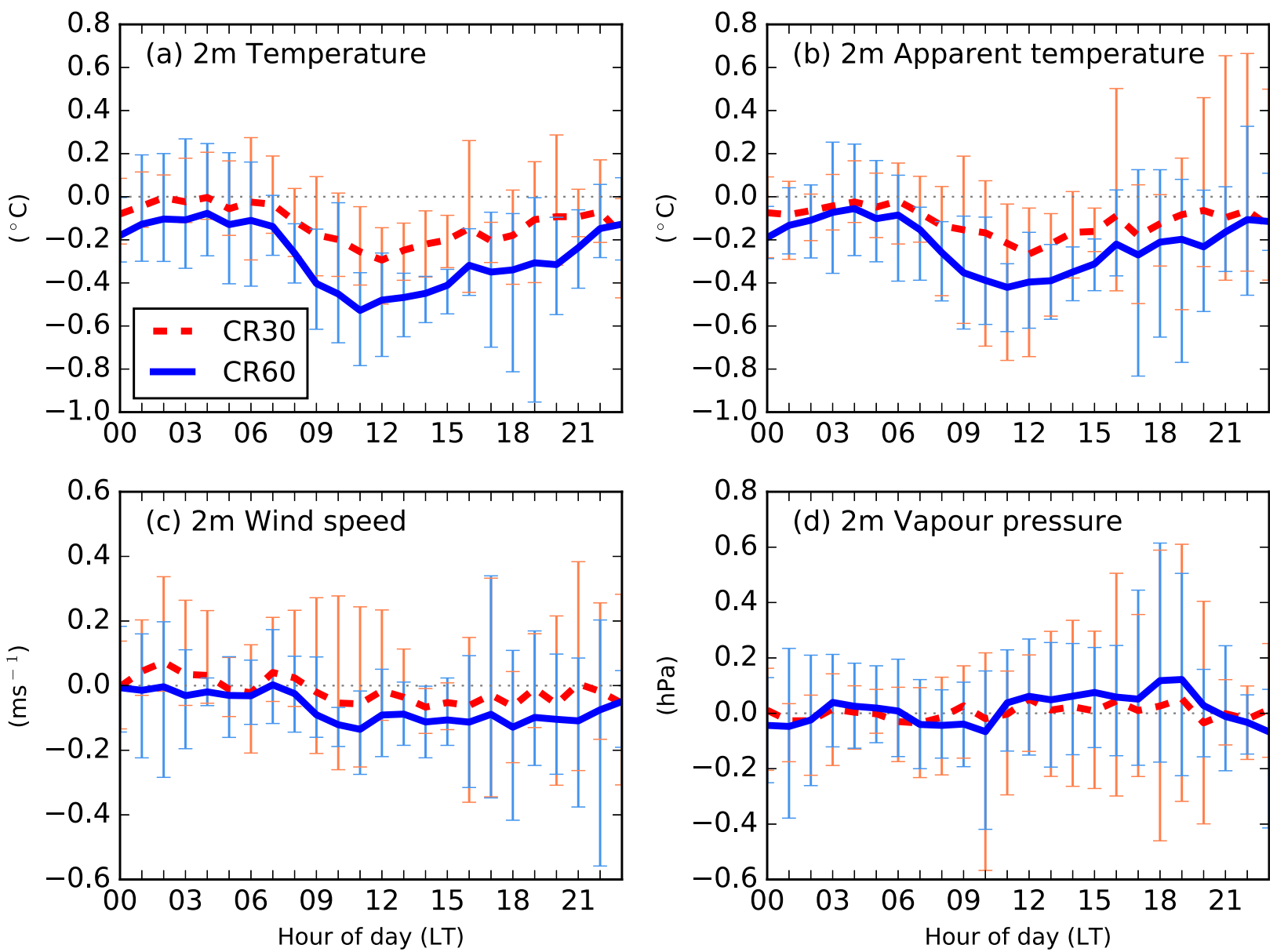

FIG. 2. The 24-h difference between the CR30 (red) and CR60 (blue) scenarios for (a) temperature, (b) AT, (c) wind speed, and (d) vapor pressure and the control simulation averaged over all urban areas of domain 2 (Fig. 1b) and across the 39 heat wave days. The error bars represent the 5th and 95th percentile for each area-averaged hour as based on the 39 heat wave days, and the thin horizontal dotted line represents no difference between the scenarios and the control.

and Laverton biases are within the range of wind speed biases found by Evans et al. (2012), hence the WRF wind speeds are appropriate for use in this study.

\section{b. Cool roofs}

The citywide average response (i.e., averaged across all urban points in domain 2) to each scenario, averaged across all heat wave days is now described. The CR30 scenario causes a maximum reduction in temperature of $0.3^{\circ} \mathrm{C}$ at 1200 relative to the control. The CR60 scenario causes a maximum reduction in temperature of $0.5^{\circ} \mathrm{C}$ at 1100 LT relative to the control (Fig. 2a). The cooling response for the CR30 scenario is shown in all heat waves from 1100 to 1500 , whereas the CR60 scenario has cooling in all heat waves from 0800 to 1800 LT. This is because in the CR60 scenario the reduction in temperature relative to the control extends into the night with an average cooling effect of $0.2^{\circ} \mathrm{C}$ from 2000 to $0700 \mathrm{LT}$ during the 39 heat wave days (Fig. 2a). The reductions in temperature at night occur because the daytime roof heat storage decreases because of the increased albedo (Li et al. 2014). Overall, cool roofs cause a statistically significant reduction in temperature.

The typical cooling response varies across the city, highlighting the spatial variability in the response due to the different urban densities and distance from the geographical center of Melbourne. In the CR60 scenario, the denser inner eastern suburbs of Melbourne cooled by up to $0.9^{\circ} \mathrm{C}$ between 1100 and $1500 \mathrm{LT}$ (Fig. 3a), because they have a higher density of rooftops to reflect the incoming solar radiation. The western and outer suburbs of Melbourne do not experience as much cooling in the CR60 scenario as they are lower density. There is spatial inter-heat wave variability between each of the 12 heat waves in the CR60 scenario (Fig. 1 in the online supplemental material), indicating that cool roofs may be more effective in different regions of Melbourne during different events. While this highlights the need to 
(a) T2

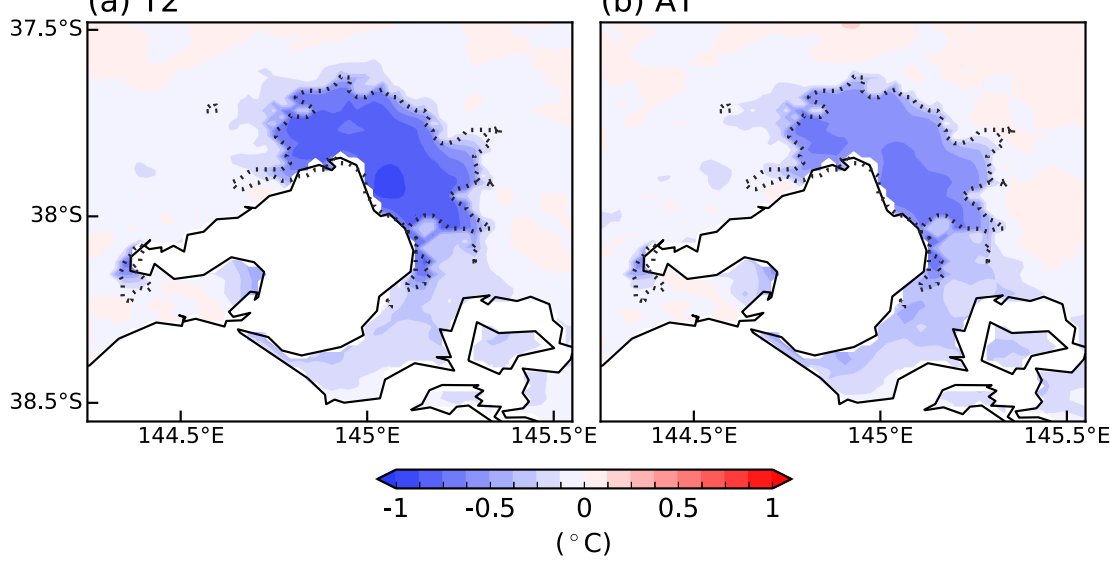

(c) AT minus T2

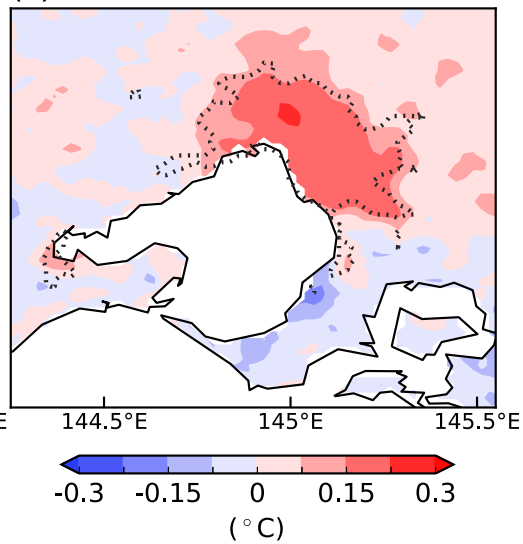

FIG. 3. The difference between the CR60 scenario and the control for (a) 2-m temperature (T2) and (b) AT, and (c) AT minus T2 for the CR60 scenario. All plots are averaged over 1100-1500 LT for the 39 heat wave days. This map has been zoomed in to focus on Melbourne (boundaries shown by the dotted line) within domain 2 .

investigate multiple events, most heat waves show the largest response to cool roofs occurring in the eastern suburbs.

The largest reduction in temperature from cool roofs occurs at 1100 and 1200 LT for the CR60 and CR30 scenario, respectively, when solar radiation is almost at its peak. This is because shortwave radiation is reflected rather than absorbed by the roofs. This translates to a reduction in average net radiation (sensible heat flux + latent heat flux - ground heat flux) at the surface of $24.1 \mathrm{~W} \mathrm{~m}^{-2}$ per day between the CR60 scenario and the control, averaged across all urban points for the 39 heat wave days. This reduction increases in magnitude to $76.5 \mathrm{~W} \mathrm{~m}^{-2}$ during the solar maximum at $1300 \mathrm{LT}$ (daylight savings time).

The reduction in net radiation overwhelmingly translates to a reduction in the energy available for sensible heat (Fig. 4), which accounts for $90.0 \%$ of the net radiation energy partition difference between the CR60 scenario and the control. The implementation of cool roofs and the subsequent reduction in the net heat flux also reduces the energy partitioned into the ground heat flux throughout the day as less energy is absorbed and stored by buildings through their rooftops (Fig. 4). As a result, the sensible heat and ground heat flux are 62.4 and $7.0 \mathrm{~W} \mathrm{~m}^{-2}$ smaller at the solar maximum for the CR60 scenario than for the control. These results show that changes to urban rooftops can have a noticeable effect at the surface.

The reduction in 2-m AT under the cool roof scenarios is very similar to the $2-\mathrm{m}$ air temperature because temperature is the strongest modulator of AT as per Eq. (1) (Fig. 2b). There is a pronounced cooling relative to the control simulation during the middle of the day in which the average AT is reduced by $0.3^{\circ} \mathrm{C}$ at 1200 for the $\mathrm{CR} 30$ scenario and $0.4^{\circ} \mathrm{C}$ at 1100 for the CR60 scenario. For the apparent temperature, cool roofs are the most effective between 1000 and 1300. At these times the inter-heat wave variability is smaller in the CR60 scenario as indicated by the 5 th and 95 th percentiles being smaller than the percentiles for the CR30 scenario. This indicates that the CR60 scenario has more certainty for a reduction in the apparent temperature during heat waves.

The apparent temperature does not decrease as much as the 2-m temperature in the cool roofs scenarios because of a reduction in wind speed and slight increase in

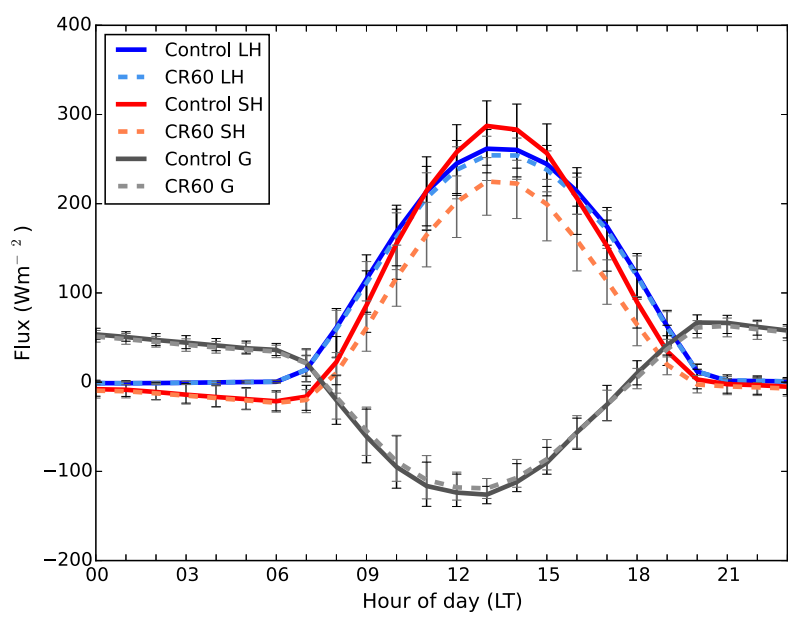

FIG. 4. The 24-h sensible heat (red), latent heat (blue), and ground heat flux (gray) for the control simulation (solid line) and the CR60 scenario (dashed line), averaged over all urban areas of domain 2 and 39 heat wave days. The error bars represent the 5 th and 95th percentile for each area-averaged hour as based on the 39 heat wave days. 

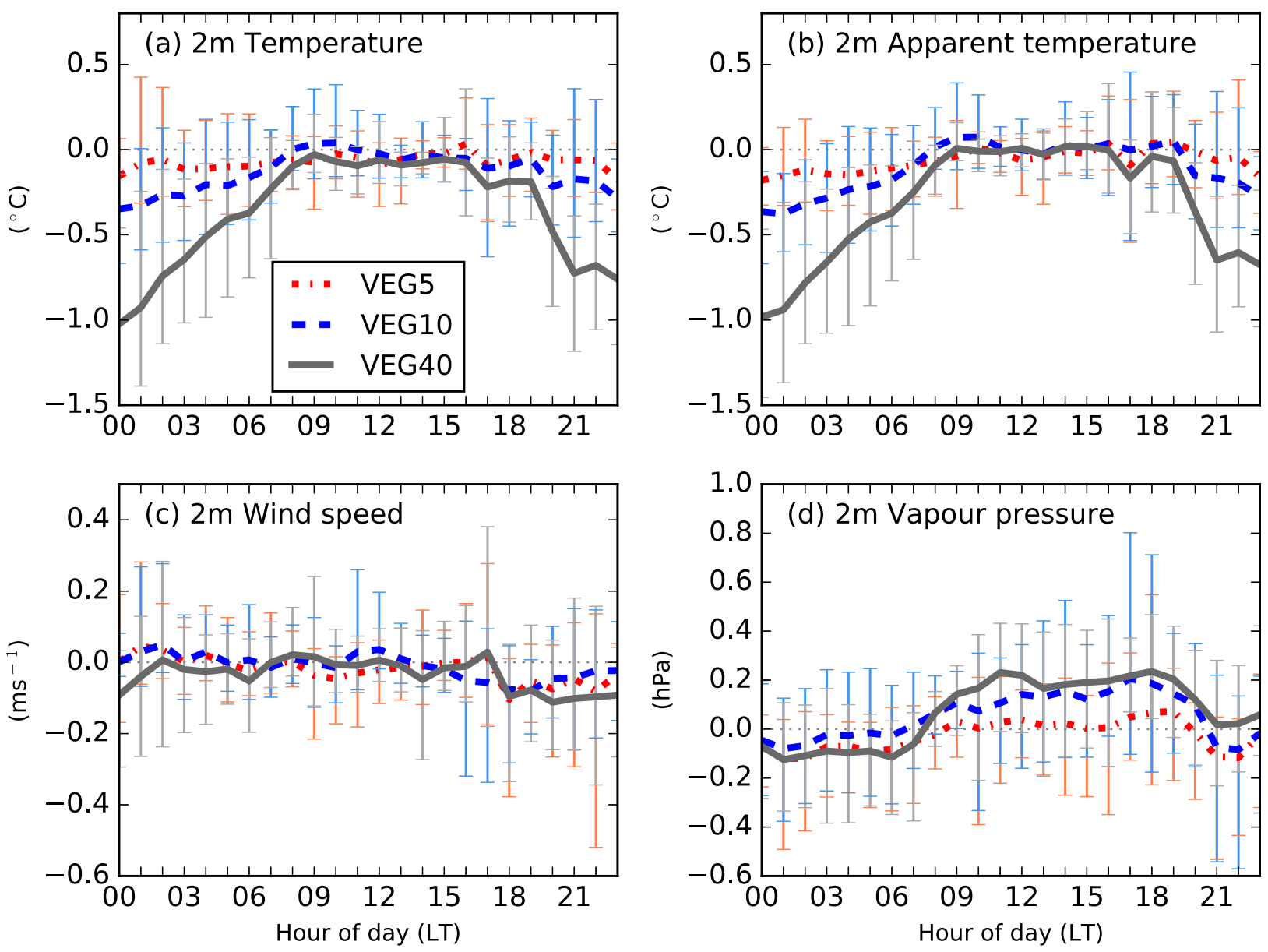

FIG. 5. As in Fig. 2, but between the VEG5 (red), VEG10 (blue), and VEG40 (gray) scenarios.

vapor pressure during the day (Figs. 2c,d). Similar results were reported by Ma et al. (2018) in a study for Sydney, Australia. The reduction in net radiation flux away from urban surfaces (Fig. 4) produces less heating and vertical mixing in the boundary layer and lower wind speeds. Consequently, the height of the boundary layer is up to $88 \mathrm{~m}$ lower during the day for the CR60 scenario (not shown). This also has implications for vapor pressure as less vertical mixing means that humidity near the surface is less likely to be mixed away, resulting in slightly higher levels of near-surface moisture (Fig. 2d). However, the inter-heat wave variability suggests that the average signal may not occur in every heat wave.

Spatially, the inner eastern suburbs of Melbourne experience the greatest reduction in AT in the CR60 scenario, whereas the lower-density outer suburbs of Melbourne experience almost no reduction in the AT from cool roofs under heat wave conditions (Fig. 3b). This is highlighted by the differences between the temperature and AT, reaching $0.2^{\circ} \mathrm{C}$ in the central, northern, and eastern suburbs (Fig. 3c).

\section{c. Increased vegetation}

In Melbourne, the modeled heat wave temperatures decrease at night when vegetation is increased (Fig. 5a). This is in contrast to the cool roof scenarios that have greater reductions of temperature during the day. The largest reductions occurred at midnight when the average VEG5, VEG10, and VEG40 scenarios are $0.2^{\circ}, 0.3^{\circ}$, and $1.0^{\circ} \mathrm{C}$ cooler than the control, respectively (Fig. 5a). The VEG5 and VEG10 scenarios do not have cooling in every heat wave as the 5th and 95th percentiles show warming during some events. However, the VEG40 scenario has significant nighttime cooling in every heat wave. This section will mostly focus on the VEG40 scenario because it shows the largest changes. Spatially, cooling of up to $2.4^{\circ} \mathrm{C}$ occurs in parts of Melbourne's north and west between 2200 and 0200 for the VEG40 scenario relative to the control (Fig. 6a). These times are chosen to illustrate the maximum effects of vegetation across the city. As with cool roofs, there is inter-heat wave variability where increased vegetation can have a 
(a) T2

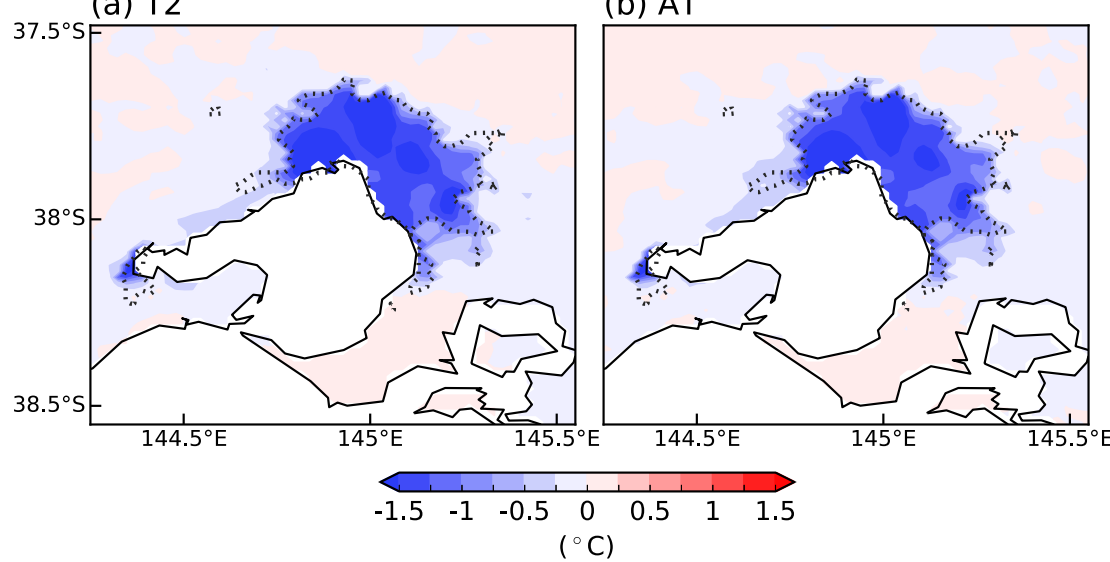

(c) AT minus T2

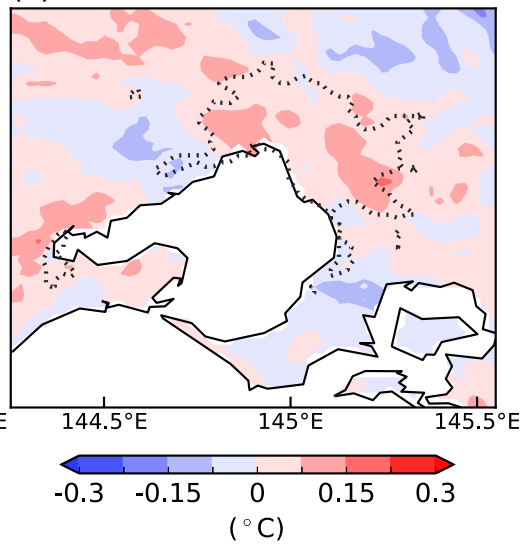

FIG. 6. As in Fig. 3, but between the VEG40 scenario and the control and all plots are averaged over 2200-0200 for the 39 heat wave days. This map has zoomed in to focus on Melbourne (boundaries shown by the dotted line) within domain 2.

larger effect on different parts of the city, depending on the heat wave event (Fig. 2 in the online supplemental material). Nevertheless, the northern suburbs most commonly have the largest cooling effect.

The reduction in modeled air temperature from increased vegetation is primarily related to the reduction in the ground heat flux and heat storage (changed heat capacity) in the city (Table 4). When impervious surfaces such as concrete and bitumen are replaced with pervious surfaces such as vegetation, the surface volumetric heat storage capacity of the city is reduced (Oke 1987). For example, the ground heat flux is $22.5 \mathrm{~W} \mathrm{~m}^{-2}$ smaller for VEG40 than the control at 1200 and $8.8 \mathrm{~W} \mathrm{~m}^{-2}$ smaller at $0000 \mathrm{LT}$, when the largest reduction in temperature occurs (Table 4). This indicates that less energy is absorbed during the day and emitted at night. Although a reduction of $8.8 \mathrm{~W} \mathrm{~m}^{-2}$ at 0000 may seem small, at this time of night the ground heat flux accounts for $78.6 \%$ of the nighttime fluxes, with sensible heat accounting for $19.0 \%$ and the latent heat flux $2.4 \%$. This reduction in heat loss from the ground causes the 2-m temperature to be cooler at night when compared with the control. Furthermore, we find that increasing vegetation has an effect at the subgrid scale. In the control scenario at night, the vegetated fraction of the grid cell has a sensible heat flux into the surface. Increasing vegetation reduces the size of this flux. Therefore, the vegetation surface temperature is reduced causing the gridcell average surface temperature to decrease. Hence, two mechanisms cause temperatures to decrease at night: a reduction in the ground heat flux and a reduction in the nighttime vegetation surface temperature.

The 2-m temperature in the VEG40 scenario remains approximately unchanged relative to the control between 0900 and 1600 (Fig. 5a). This contradicts the expectation that increasing vegetation would increase evapotranspiration, causing evaporative cooling. This expectation is based on the hypothesis that increasing the vegetation fraction changes the net radiation energy partitioning toward a scenario where more energy is available for latent heat exchange because of the larger amounts of vegetation and exposed soil, subsequently enabling more evaporation from the urban grid cell. Indeed, the VEG40 scenario has a latent heat flux that is $36 \mathrm{~W} \mathrm{~m}^{-2}$ higher at 1200 when compared with the control (Table 4). This increase in the latent heat flux occurs even in the presence of an intensely dry top soil layer that is close to wilting

TABLE 4. The surface sensible heat, latent heat, and ground heat flux for the control simulation and the VEG40 scenario, spatially averaged over all urban areas in domain 2 and 39 heat wave days. Positive denotes a flux into the atmosphere.

\begin{tabular}{|c|c|c|c|c|c|c|}
\hline \multirow[b]{2}{*}{ Time } & \multicolumn{2}{|c|}{ Sensible heat flux $\left(\mathrm{W} \mathrm{m}^{-2}\right)$} & \multicolumn{2}{|c|}{ Latent heat flux $\left(\mathrm{W} \mathrm{m}^{-2}\right)$} & \multicolumn{2}{|c|}{ Ground heat flux $\left(\mathrm{W} \mathrm{m}^{-2}\right)$} \\
\hline & Control & VEG40 & Control & VEG40 & Control & VEG40 \\
\hline 1200 & 257.8 & 246.3 & 244.9 & 280.9 & -124.1 & -101.6 \\
\hline 1500 & 257.3 & 242.2 & 244.3 & 281.7 & -90.1 & -75.8 \\
\hline 1800 & 90.5 & 74.3 & 121 & 140.4 & 9.4 & 4.5 \\
\hline 2100 & -1.6 & -8.2 & 1.5 & 1.8 & 67.7 & 54.6 \\
\hline 0000 & -8 & -10.8 & -1.1 & -1.4 & 53.8 & 45 \\
\hline
\end{tabular}


point (soil moisture fraction of 0.06 at $1200 \mathrm{LT}$ ) and the direct evaporation from soil being zero. The increase in latent heat flux occurs because the vegetation is able to access water from the deeper soil horizons, that is, the top three soil layers in the model where the soil moisture fraction is higher at $\sim 0.19$. However, this increase in the latent heat flux does not translate to a reduction in daytime 2-m temperature through evaporative cooling, because the change in flux is relatively small.

The potential cooling from increased vegetation is only governed by the difference in urban fraction between the vegetation scenarios and the control. Although the vegetation component of the urban grid cell always has a lower surface temperature than the urban component, both the urban and vegetated fractions have very high surface temperatures during the day. This is because of the extreme heat wave temperatures causing each part of the grid cell to be extremely warm. Therefore, by increasing the vegetation fraction, the temperature is unlikely to greatly decrease as the vegetated surface is a similar temperature to the urban surface. While changing the vegetation fraction is effective at reducing nighttime temperatures, its effects are smaller during the day because the net radiation is much larger and less sensitive to changes in the ground heat flux.

Across all vegetation scenarios, the largest reduction in AT occurs at midnight when the average VEG40 scenario is $1.0^{\circ} \mathrm{C}$ cooler than the control (Fig. 5b). This is almost identical to the 2-m temperature, including the VEG40 scenario having significant nighttime cooling in all heat wave events (Fig. 5a). This is because the other modulators of AT, wind speed and vapor pressure, do not significantly change at night (Figs. 5c,d).

The VEG40 spatial pattern of the nighttime reduction in AT relative to the control is similar to the temperature (Figs. 6a,b). Indeed, the difference between the spatial pattern of the temperature and AT is almost negligible (Fig. 6c), which is in contrast to the CR60 scenario. Therefore, because the differences are small, these results suggest that additional vegetation does not adversely affect human thermal comfort at night during heat waves.

During the day the city-averaged difference between the AT in the VEG40 scenario and the control is negligible because of a concurrent increase in vapor pressure by approximately $0.2 \mathrm{hPa}$ (Fig. 5d). Thus, increasing urban vegetation creates a slightly more humid environment during heat waves. The resulting effect of the added humidity on the daytime apparent temperature is minimal when compared with the reduction in nighttime apparent temperature that adding vegetation supplies. Because heat waves are most dangerous at night, adding vegetation would have immediate health benefits on an urban community.
TABLE 5. The 2-m temperature for each scenario minus the control averaged over the 39 heat wave days for all urban areas in domain 2. The values are separated into the 24-h average, the daytime, and the nighttime. Boldface type indicates that the combination of mitigation strategies produces more cooling than the individual strategies added together, and italics indicate that the combination of strategies is less than the individual strategies added together.

\begin{tabular}{lccc}
\hline \hline \multicolumn{1}{c}{ Scenario } & 24-h avg & $\begin{array}{c}\text { Day } \\
(0700-2000)\end{array}$ & $\begin{array}{c}\text { Night } \\
(2100-0600)\end{array}$ \\
\hline CR30 $\left({ }^{\circ} \mathrm{C}\right)$ & -0.1 & -0.2 & -0.1 \\
CR60 $\left({ }^{\circ} \mathrm{C}\right)$ & -0.3 & -0.4 & -0.1 \\
VEG5 $\left({ }^{\circ} \mathrm{C}\right)$ & -0.1 & -0.1 & -0.1 \\
VEG10 $\left({ }^{\circ} \mathrm{C}\right)$ & -0.1 & -0.1 & -0.2 \\
VEG40 $\left({ }^{\circ} \mathrm{C}\right)$ & -0.4 & -0.1 & -0.7 \\
VEG5CR30 $\left({ }^{\circ} \mathrm{C}\right)$ & -0.2 & -0.2 & -0.2 \\
VEG5CR60 $\left({ }^{\circ} \mathrm{C}\right)$ & -0.3 & -0.4 & $\mathbf{- 0 . 4}$ \\
VEG10CR30 $\left({ }^{\circ} \mathrm{C}\right)$ & $-\mathbf{0 . 3}$ & -0.2 & -0.3 \\
VEG10CR60 $\left({ }^{\circ} \mathrm{C}\right)$ & -0.4 & -0.4 & $\mathbf{- 0 . 4}$ \\
VEG40CR30 $\left({ }^{\circ} \mathrm{C}\right)$ & -0.5 & -0.3 & -0.8 \\
VEG40CR60 $\left({ }^{\circ} \mathrm{C}\right)$ & -0.6 & -0.4 & -0.8 \\
\hline
\end{tabular}

\section{d. Mitigation strategies in combination}

A combination of increased vegetation and cool roofs is the most efficient way to mitigate urban heat throughout a heat wave. The evidence here shows that each reduces temperatures in a complementary way: cool roofs have an effect during the day and increased vegetation works at night (Table 5). As is expected, the most effective heatmitigation scenario during the heat wave days is that with the greatest intervention. Namely, the VEG40CR60 scenario, which recorded $0.6^{\circ} \mathrm{C}$ of cooling during the heat wave, increasing to $0.82^{\circ} \mathrm{C}$ of cooling at night (2100-0600) when averaged over all urban areas and heat wave days (Table 5). The VEG40CR60 combination represents a version of Melbourne with $40 \%$ urban vegetation and $60 \%$ cool roofs. The largest changes in the VEG40CR60 scenario occur in the medium- and high-density urban areas that have reductions in temperature of $0.9^{\circ}$ and $0.8^{\circ} \mathrm{C}$, respectively. On average, the medium-density areas have a larger reduction in temperature relative to the control than the high-density areas, because they exhibit more cooling at night, particularly between 2000 and 0100 (Fig. 7). This is because the sensible heat flux for medium-density urban areas has a larger decrease in the VEG40CR60 scenario when compared with the high-density areas. The low-density urban areas in the VEG40CR60 scenario have an average cooling of $0.4^{\circ} \mathrm{C}$ across the $24 \mathrm{~h}$ of the heat wave days. The low-density category includes small towns often represented as one urban grid point surrounded by rural areas, where the effects of changing the urban surface are smaller than in the city. This contributes to the large difference in cooling between the low- and medium-density urban areas. 


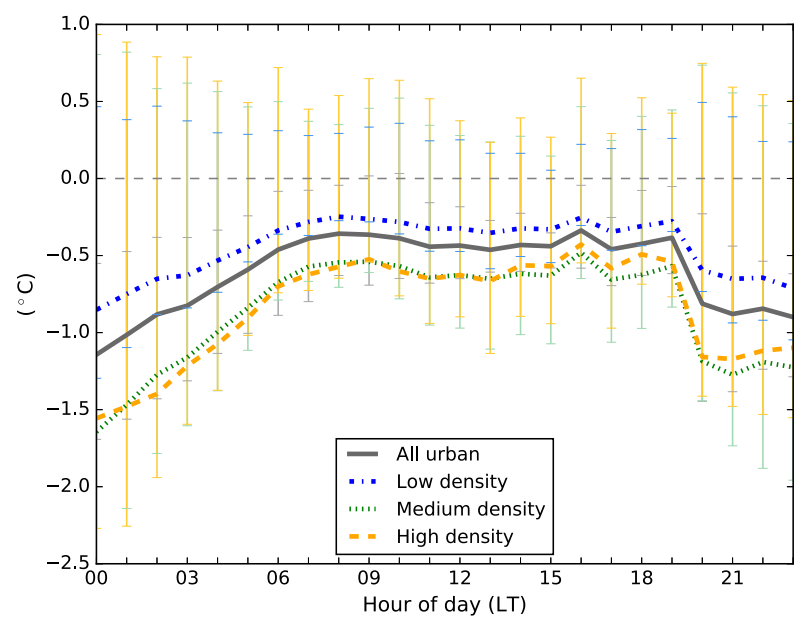

FIG. 7. The difference in T2 between the VEG40CR60 scenario and the control for low-density, medium-density, high-density, and all urban areas. The error bars represent the 5 th and 95 th percentile for each area-averaged hour as based on the 39 heat wave days.

When the high-impact VEG40CR60 scenario is applied, large areas of Melbourne show temperature reductions of up to $1.5^{\circ} \mathrm{C}$ during heat wave conditions (Fig. 8a). The largest cooling in AT is more localized with maximum cooling occurring in the inner northwestern suburbs and the far northern suburbs. Here, there are reductions in $\mathrm{AT}$ of up to $1.3^{\circ} \mathrm{C}$, whereas the remainder of the city only cools by approximately $0.5^{\circ}-0.7^{\circ} \mathrm{C}$ (Fig. $8 \mathrm{~b}$ ). Over all of Melbourne the AT does not cool as much as the temperature because of a concurrent decrease in wind speed (Fig. 8c) and increase in vapor pressure (Fig. 8d). The increase of vapor pressure is unlikely to affect human thermal stress as heat waves in Melbourne are associated with dry conditions. Indeed, the control scenario has a relative humidity of $48 \%$ when spatially averaged over Melbourne and the 39 heat wave days.

An increase in daytime evaporation from more vegetation increases the vapor pressure across Melbourne in the VEG40CR60 scenario (Fig. 8d). This is especially noticeable in the medium-density, leafy eastern suburbs of Melbourne. In contrast, the inner northwestern suburbs experience almost no change in vapor pressure resulting in greater cooling of the AT. The distinct difference in vapor pressure between the eastern and western suburbs of Melbourne is likely due to the spatial distribution of soil types in WRF. On the western side of the city the most common soil types are clay and sandy clay loam, whereas on the eastern side the soils are mostly loam or sandy loam. The representation of these soil types in WRF (i.e., heat capacity, saturation point, and wilting point) partly causes the difference in evaporation potential between east and west, and hence vapor pressure, where the eastern suburb soils have the potential to hold more water. This highlights that the west of Melbourne would benefit from the cooling of increased vegetation without raising human thermal stress due to increased humidity. Therefore, it could be advised that the western suburbs adopt a greening approach to urban heat mitigation.

The combination scenarios show either a negligible or very small nonlinear interaction on the order of $0.1^{\circ} \mathrm{C}$ (Table 5). If the interaction is nonlinear, the combination is sometimes greater than the sum of its parts, while in others it is less. For example, the 24-h heat wave average VEG40 and CR30 scenarios individually reduce the heat wave temperature by $0.4^{\circ}$ and $0.1^{\circ} \mathrm{C}$, respectively, and the combination reduces heat wave temperatures by $0.5^{\circ} \mathrm{C}$ with a negligible nonlinear interaction (Table 5). However, when differences occur such as in the VEG10CR60 scenario, which shows a combination 1) less than the sum of its parts during the day, 2) greater than the sum of its parts at night, and 3) overall no difference, it is likely due to weather noise among the ensembles of simulations. The small magnitude of the noise is further indicated by the spatial randomness of the differences between combination scenarios and the sum of their parts (Fig. 9). This result is contrary to the expectation of interactions between the two strategies, as cool roofs and vegetation affect the climate through different mechanisms.

\section{Discussion and conclusions}

Many factors, including the large-scale weather conditions, the climate, and the geography of a city, affect the capacity of cool roofs and increased vegetation to reduce urban temperatures. Our results compare well to similar studies from cities around the world showing that cool roofs can provide effective cooling on a citywide scale ( $\mathrm{Li}$ et al. 2014; Synnefa et al. 2008; Millstein and Menon 2011). We have shown that this is also the case when a more realistic fraction of cool roofs are employed.

Li et al. (2014) used WRF and PUCM to model the viability of cool roofs under heat wave conditions for the Baltimore-Washington, D.C., metropolitan area. They found that if $70 \%$ of the buildings had cool roofs, then the 2-m urban heat island decreased by approximately $0.4^{\circ} \mathrm{C}$ at 1200 . While a reduction in the urban heat island is different from the change in urban-only $2-\mathrm{m}$ temperature calculated in this study, this value is comparable to our CR60 results. Synnefa et al. (2008) modeled the effectiveness of cool roofs in Athens using MM5 (Grell et al. 1994) for one representative clear summer day with a maximum temperature of $35.3^{\circ} \mathrm{C}$. They found that when the roof albedo for all the buildings is raised from 0.18 to 0.85 the $2-\mathrm{m}$ temperature across the city is 
(a) $2 \mathrm{~m}$ temperature

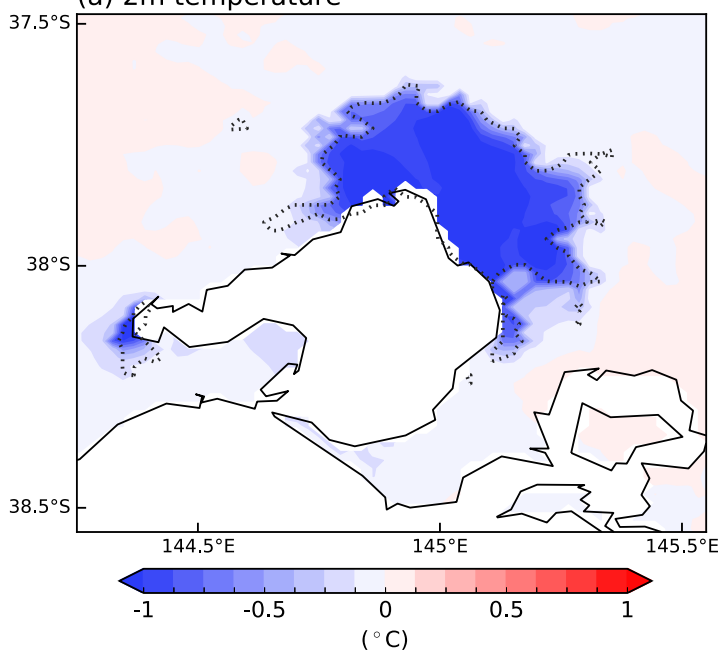

(c) $2 \mathrm{~m}$ Wind speed

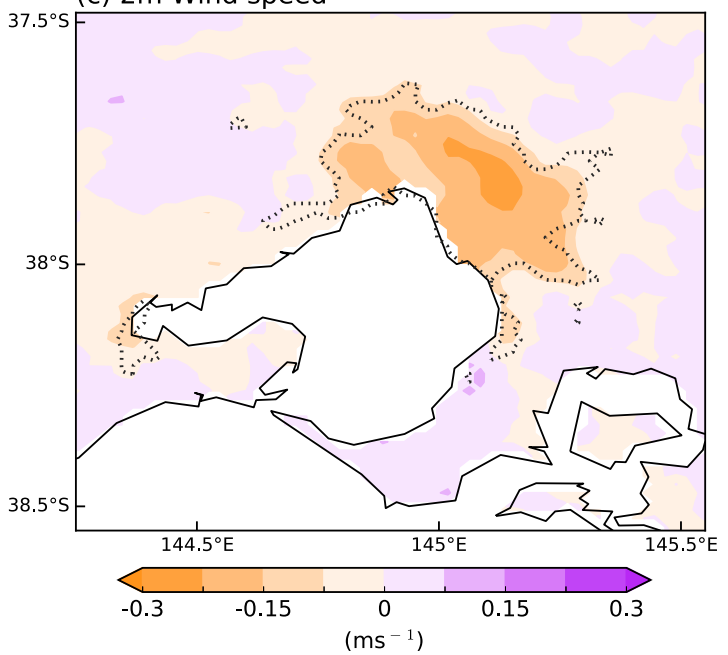

(b) $2 m$ Apparent temperature

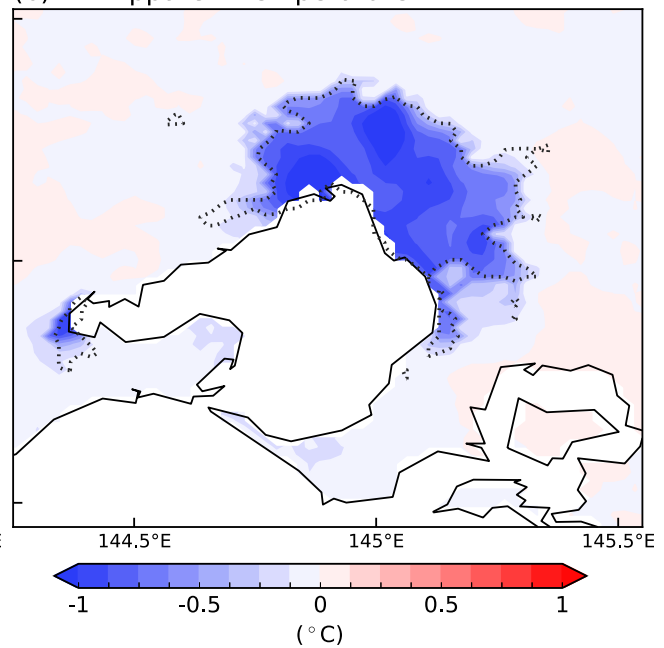

(d) $2 \mathrm{~m}$ Vapour pressure

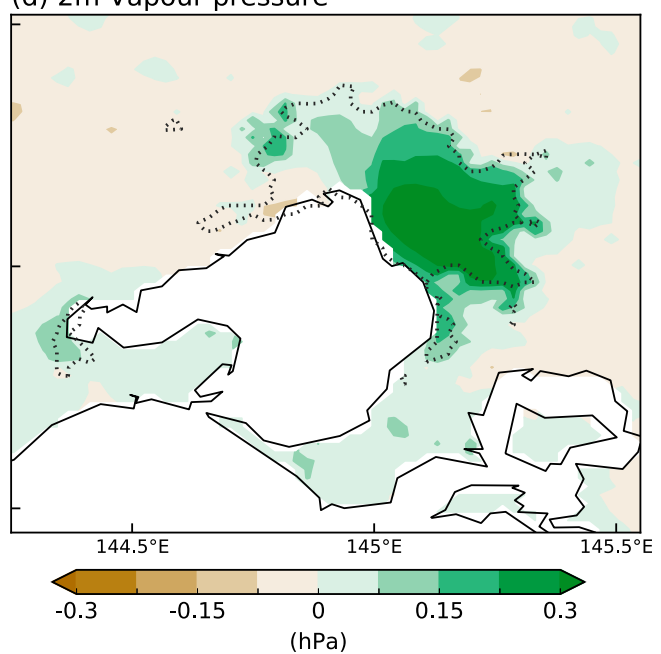

FIG. 8. The difference in (a) T2, (b) AT, (c) wind speed, and (d) vapor pressure between the VEG40CR60 scenario and the control averaged over $24 \mathrm{~h}$ and the 39 heat wave days. This map has been zoomed in to focus on Melbourne (boundaries shown by the dotted line) within domain 2.

reduced by up to $1.5^{\circ} \mathrm{C}$ at 1200 . In contrast, Millstein and Menon (2011) use WRF to model cities in the continental United States for 11 years where cities had adopted a +0.25 and +0.15 change in albedo for roofs and pavements respectively, representing the implementation of cool roofs and cool pavements across the city. They found that the average reduction in temperature for the 10 most populous cities is $0.22^{\circ} \mathrm{C}$ for summer and $0.18^{\circ} \mathrm{C}$ for winter. However, some cities such as Atlanta, Georgia, show a larger cooling effect in winter than summer because of differences in radiation from that fact that Atlanta is cloudier and more humid in summer and is drier and clearer in winter. This indicates that the local climate can influence the effectiveness of cool roofs and cool pavements.
Past studies have shown that changing the vegetation fraction is the largest contributor to differences in the urban heat island, in comparison with other variables in the WRF urban properties table such as building height (Chen et al. 2014). This indicates that the heatmitigation potential is large, but also that WRF is sensitive to changes in the vegetation fraction. There is also seasonality in the effectiveness of cooling from increasing vegetation. Cui and De Foy (2012) used WRF to investigate how increases in the vegetation fraction affect the urban heat island during different seasons in Mexico City by looking at events in March, July, August, October, and December. They found that when the vegetation fraction is increased to $40 \%$, the largest reduction in the near-surface urban heat island at night 
(a) VEG40CR30 minus (VEG40 + CR30)

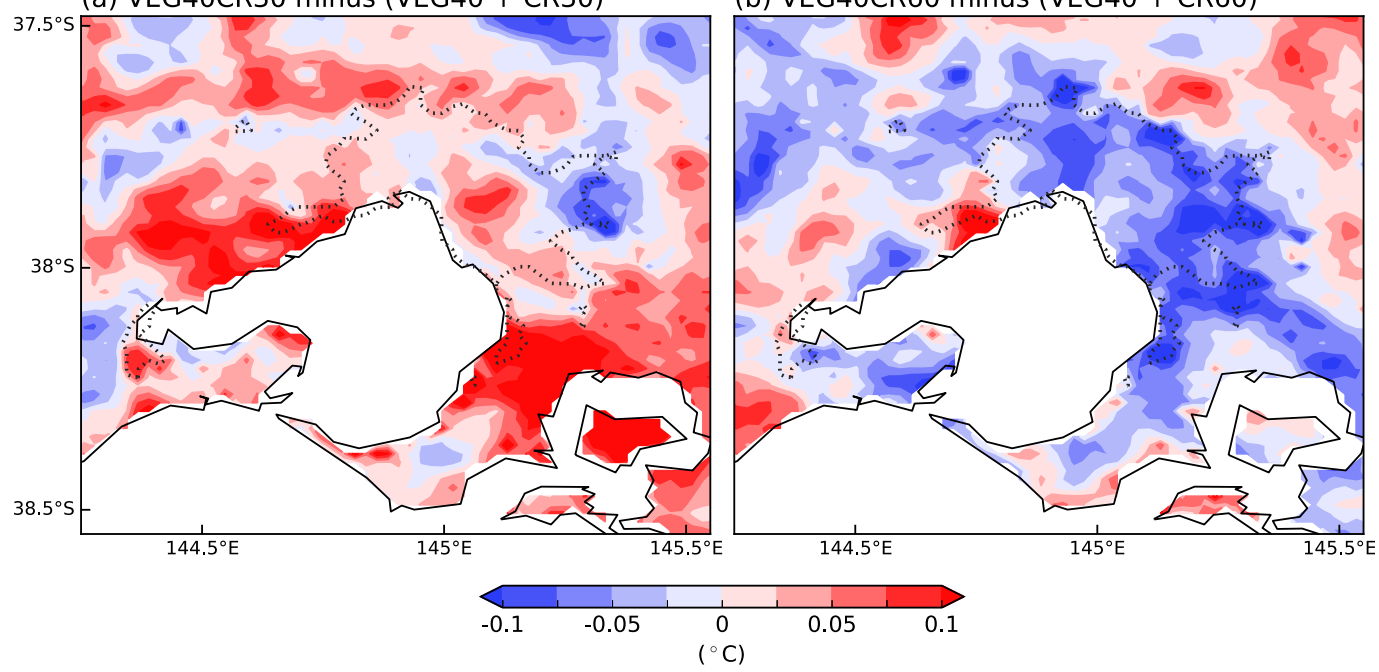

FIG. 9. The respective differences in T2 between the combination scenarios (a) VEG40CR30 and (b) VEG40CR60 and the sum of their individual parts averaged over $24 \mathrm{~h}$ of the 39 heat wave days. This map has been zoomed in to focus on Melbourne (boundaries shown by the dotted line) within domain 2.

occurs during March, whereas the largest reduction in daytime near-surface urban heat island occurs in July. Papangelis et al. (2012) examined an increase in the urban vegetation fraction in Athens using WRF under typical warm-season day conditions. Athens and Melbourne both have Mediterranean climates of hot and dry summers. When the vegetation fraction was increased from $27 \%$ to $50 \%$ Papangelis et al. (2012) found that nights cooled by $1.9^{\circ} \mathrm{C}$ with no cooling during the daytime. These results are very similar to the findings of our VEG40 scenario in which the average vegetation fraction across low-, medium-, and high-density urban increased from $27 \%$ to $40 \%$, and the cooling at night reached $1.5^{\circ} \mathrm{C}$ (Fig. 6a).

There are three limitations to the increased vegetation aspect of this study. First, the almost doubling of urban vegetation in the VEG40 scenario is based on a City of Melbourne local government policy to have $40 \%$ tree canopy cover by 2040 . However, the vegetation simulated by the cropland/natural vegetation mosaic does not indicate tall trees across urban areas and is instead a mix of low vegetation. Therefore, the shadow cooling effects and temperature changes from evapotranspiration above the tree canopy are underestimated in the increased vegetation scenarios and do not fully represent the $40 \%$ canopy cover objective. The species selected for the increased vegetation mitigation scenario must also be considered, as spatial diversity helps protect vegetation from pests, disease, and stress due to climate change (City of Melbourne Council 2013). Second, the increase in urban vegetation in WRF occurs by removing urban surfaces and replacing them with vegetation, rather than increasing the vegetation inside the canyon. This is not realistic for Melbourne, particularly as its population is increasing rapidly. Last, the cropland/natural vegetation mosaic category for urban vegetation does not accurately represent the current distribution of plant types across Melbourne, because WRF assumes a uniform distribution of vegetation types. The Noah LSM extra vegetation is simulated to have a deep root system, but most trees in Melbourne, except those in the inner suburbs, have a shallow root system (City of Melbourne 2013). This is because Australian vegetation is very different from that in the northern United States or Europe (Moore et al. 2016), meaning that it may not be represented as accurately in the U.S.-designed model, which would affect the results of the study.

This study shows that, across the city of Melbourne, there are regional differences in the efficacy of the mitigation strategies investigated during heat waves. The western suburbs of Melbourne are climatologically drier, have less vegetation, and, as a result, can experience warmer daytime temperatures than the eastern suburbs because of higher sensible heating. In WRF the western suburbs are also represented with drier soils types, meaning that an increase in vegetation does not lead to an overly humid near-surface environment. Therefore, the western suburbs have a larger cooling potential from increased vegetation when compared with cool roofs, where the added humidity does not negatively affect human thermal comfort. Citizens in Melbourne's west have a high vulnerability index to heat-related illness because of their higher proportion of 
elderly residents and immigrants (Loughnan et al. 2013). To confront this issue regional governments and other sectors have created the Greening the West initiative (http://greeningthewest.org.au/). Their strategy is that increased parks and green spaces in the western suburbs will benefit the environment, the economy, and the health and well-being of residents. Our results confirm the potential health benefits of this initiative in the western suburbs. In contrast, the eastern suburbs of Melbourne experience greater reductions in temperature from cool roofs than does the rest of Melbourne because of their higher urban density. Hence, cool roofs as a heat-mitigation measure would provide more tangible cooling in the eastern suburbs than increased vegetation.

Our results have shown that increasing both the albedo of roofs and the proportion of vegetation in Melbourne is an effective approach to reducing the 2-m temperature under heat wave conditions. In particular, the VEG40CR60 scenario can reduce urban heat wave temperatures by up to $1.5^{\circ} \mathrm{C}$ across the Melbourne urban area (Fig. 8a). This cooling is small in magnitude relative to maximum temperatures of over $40^{\circ} \mathrm{C}$ that are often experienced during heat waves, but evidence from past studies shows that even a slight reduction has the potential to save lives. For example, research done by Nicholls et al. (2008) for Melbourne shows that if the mean daily temperature of today's maximum and tomorrow morning's minimum temperature is reduced from $30^{\circ}$ to $28^{\circ} \mathrm{C}$ it could save 1 person per 100000 people. Melbourne has a population of nearly 5 million, meaning that an average of 50 extra lives could be saved during strong heat events.

Our study has assessed the temperature and human thermal stress response to two commonly proposed urban heat-mitigation strategies for Melbourne under heat wave conditions. We have found that increasing vegetation is more efficient at reducing temperatures in the western suburbs of Melbourne, whereas the implementation of cool roofs is more efficient at reducing temperatures in the eastern suburbs of Melbourne. However, a combination of the scenarios is the most effective at reducing temperatures across Melbourne. For human thermal stress, both mitigation strategies modestly increase near-surface humidity, which could increase stress, yet this is counterbalanced by the reduction in temperature. This reduction would improve human thermal stress and reduce the risk of mortality during heat waves.

Acknowledgments. This research was supported by the CRC for Water Sensitive Cities, ARC DECRA project DE150101297, the ARC Centre of Excellence for Climate System Science (Grant CE 110001028), and the NCI National Facility. The authors thank Claire Carouge from the ARC Centre of Excellence for Climate System Science Computational Modelling Support team for helping to couple the PUCM to WRF, Cassandra Rogers from Monash University for helping with heat wave identification, the Australian Bureau of Meteorology for providing the AWAP and weather station data, and the ECMWF for supplying the ERAInterim data.

\section{REFERENCES}

Akbari, H., S. Menon, and A. Rosenfeld, 2009: Global cooling: Increasing world-wide urban albedos to offset $\mathrm{CO}_{2}$. Climatic Change, 94, 275-286, https://doi.org/10.1007/s10584-008-9515-9.

Albergel, C., and Coauthors, 2013: Skill and global trend analysis of soil moisture from reanalyses and microwave remote sensing. J. Hydrometeor., 14, 1259-1277, https://doi.org/ 10.1175/JHM-D-12-0161.1.

Anderson, G. B., M. L. Bell, and R. D. Peng, 2013: Methods to calculate the heat index as an exposure metric in environmental health research. Environ. Health Perspect., 121, 11111119, https://doi.org/10.1289/ehp.1206273.

Argüeso, D., J. P. Evans, L. Fita, and K. J. Bormann, 2014: Temperature response to future urbanization and climate change. Climate Dyn., 42, 2183-2199, https://doi.org/10.1007/s00382-013-1789-6.

$\longrightarrow,-$ A. J. Pitman, and A. Di Luca, 2015: Effects of city expansion on heat stress under climate change conditions. PLOS ONE, 10, e0117066, https://doi.org/10.1371/journal. pone. 0117066 .

Barlage, M., S. Miao, and F. Chen, 2016: Impact of physics parameterizations on high-resolution weather prediction over two Chinese megacities. J. Geophys. Res. Atmos., 121, 44874498, https://doi.org/10.1002/2015JD024450.

Bowler, D. E., L. Buyung-Ali, T. M. Knight, and A. S. Pullin, 2010: Urban greening to cool towns and cities: A systematic review of the empirical evidence. Landscape Urban Plann., 97, 147155, https://doi.org/10.1016/j.landurbplan.2010.05.006.

Bröde, P., D. Fiala, K. Błażejczyk, I. Holmér, G. Jendritzky, B. Kampmann, B. Tinz, and G. Havenith, 2012: Deriving the operational procedure for the Universal Thermal Climate Index (UTCI). Int. J. Biometeor., 56, 481-494, https://doi.org/ 10.1007/s00484-011-0454-1.

Chen, F., and Coauthors, 2011: The integrated WRF/urban modelling system: Development, evaluation, and applications to urban environmental problems. Int. J. Climatol., 31, 273-288, https://doi.org/10.1002/joc.2158.

— X. Yang, and W. Zhu, 2014: WRF simulations of urban heat island under hot-weather synoptic conditions: The case study of Hangzhou City, China. Atmos. Res., 138, 364-377, https:// doi.org/10.1016/j.atmosres.2013.12.005.

Chen, Y., and N. H. Wong, 2006: Thermal benefits of city parks. Energy Build., 38, 105-120, https://doi.org/10.1016/ j.enbuild.2005.04.003.

City of Melbourne, 2013: Central city urban forest precinct plan 2013-2023. City of Melbourne Council Rep., 20 pp., https:// participate.melbourne.vic.gov.au/application/files/2514/1273/ 7287/Central_City_Urban_Forest_Precinct_Plan.PDF.

Coutts, A. M., J. Beringer, and N. J. Tapper, 2007: Impact of increasing urban density on local climate: Spatial and temporal 
variations in the surface energy balance in Melbourne, Australia. J. Appl. Meteor. Climatol., 46, 477-493, https://doi.org/ 10.1175/JAM2462.1.

—_, E. Daly, J. Beringer, and N. J. Tapper, 2013: Assessing practical measures to reduce urban heat: Green and cool roofs. Build. Environ., 70, 266-276, https://doi.org/10.1016/ j.buildenv.2013.08.021.

Cowan, T., A. Purich, S. E. Perkins, A. Pezza, G. Boschat, and K. Sadler, 2014: More frequent, longer, and hotter heat waves for Australia in the twenty-first century. J. Climate, 27, 58515871, https://doi.org/10.1175/JCLI-D-14-00092.1.

Cui, Y. Y., and B. De Foy, 2012: Seasonal variations of the urban heat island at the surface and the near-surface and reductions due to urban vegetation in Mexico City. J. Appl. Meteor. Climatol., 51, 855-868, https://doi.org/10.1175/JAMC-D-11-0104.1.

Dee, D. P., and Coauthors, 2011: The ERA-Interim reanalysis: Configuration and performance of the data assimilation system. Quart. J. Roy. Meteor. Soc., 137, 553-597, https://doi.org/ 10.1002/qj.828.

Department of Environment Land Water and Planning, 2017: Plan Melbourne 2017-2050: A global city of opportunity and choice. Victoria State Government Rep., 20 pp., http://www. planmelbourne.vic.gov.au/_data/assets/pdf_file/0009/377127/ Plan_Melbourne_2017-2050_Summary.pdf.

Department of Health, 2014: The health impacts of the January 2014 heatwave in Victoria. Victoria State Government Rep., 37 pp., https://www2.health.vic.gov.au/Api/downloadmedia/ \%7BDC381402-DF8F-42A5-8153-2BDF690F5402\%7D.

Dudhia, J., 1989: Numerical study of convection observed during the Winter Monsoon Experiment using a mesoscale twodimensional model. J. Atmos. Sci., 46, 3077-3107, https://doi.org/ 10.1175/1520-0469(1989)046<3077:NSOCOD > 2.0.CO;2.

Eliasson, I., 1996: Urban nocturnal temperatures, street geometry and land use. Atmos. Environ., 30, 379-392, https://doi.org/ 10.1016/1352-2310(95)00033-X.

Evans, J. P., M. Ekström, and F. Ji, 2012: Evaluating the performance of a WRF physics ensemble over south-east Australia. Climate Dyn., 39, 1241-1258, https://doi.org/ 10.1007/s00382-011-1244-5.

Fischer, E. M., K. W. Oleson, and D. M. Lawrence, 2012: Contrasting urban and rural heat stress responses to climate change. Geophys. Res. Lett., 39, L03705, https://doi.org/ 10.1029/2011GL050576.

Gago, E. J., J. Roldan, R. Pacheco-Torres, and J. Ordóñez, 2013: The city and urban heat islands: A review of strategies to mitigate adverse effects. Renewable Sustainable Energy Rev., 25, 749-758, https://doi.org/10.1016/j.rser.2013.05.057.

Georgescu, M., P. E. Morefield, B. G. Bierwagen, and C. P. Weaver, 2014: Urban adaptation can roll back warming of emerging megapolitan regions. Proc. Natl. Acad. Sci. USA, 111, 2909-2914, https://doi.org/10.1073/pnas.1322280111.

Giannaros, T. M., D. Melas, I. A. Daglis, I. Keramitsoglou, and K. Kourtidis, 2013: Numerical study of the urban heat island over Athens (Greece) with the WRF model. Atmos. Environ., 73, 103-111, https://doi.org/10.1016/j.atmosenv.2013.02.055.

Goldie, J., L. Alexander, S. C. Lewis, and S. Sherwood, 2017: Comparative evaluation of human heat stress indices on selected hospital admissions in Sydney, Australia. Aust. N. Z. J. Public Health, 41, 381-387, https://doi.org/10.1111/ 1753-6405.12692.

Gosling, S. N., and Coauthors, 2014: A glossary for biometeorology. Int. J. Biometeor., 58, 277-308, https://doi.org/ 10.1007/s00484-013-0729-9.
Grell, G. A., J. Dudhia, and D. R. Stauffer, 1994: A description of the fifth generation Penn State/NCAR Mesoscale Model (MM5). NCAR Tech. Note NCAR/TN-398+STR, 121 pp., https://doi.org/10.5065/D60Z716B.

Heaviside, C., X.-M. Cai, and S. Vardoulakis, 2015: The effects of horizontal advection on the urban heat island in Birmingham and the West Midlands, United Kingdom during a heatwave. Quart. J. Roy. Meteor. Soc., 141, 1429-1441, https://doi.org/ 10.1002/qj.2452.

Hughes, L., E. Hanna, and J. Fenwick, 2016: The silent killer: Climate change and the health impacts of extreme heat. Climate Council Rep., 36 pp., https://www.climatecouncil.org.au/ silentkillerreport.

Imran, H. M., J. Kala, A. W. M. Ng, and S. Muthukumaran, 2018: An evaluation of the performance of a WRF multiphysics ensemble for heatwave events over the city of Melbourne in southeast Australia. Climate Dyn., 50, 25532586, https://doi.org/10.1007/s00382-017-3758-y.

Jackson, T. L., J. J. Feddema, K. W. Oleson, G. B. Bonan, and J. T. Bauer, 2010: Parameterization of urban characteristics for global climate modeling. Ann. Assoc. Amer. Geogr., 100, 848 865, https://doi.org/10.1080/00045608.2010.497328.

Jacobs, S. J., A. B. Pezza, V. Barras, and J. Rye, 2014: A new biocomfort perspective for Melbourne based on heat stress, air pollution and pollen. Int. J. Biometeor., 58, 263-275, https:// doi.org/10.1007/s00484-013-0636-0.

, T. Vihma, and A. B. Pezza, 2015: Heat stress during the Black Saturday event in Melbourne, Australia. Int. J. Biometeor., 59 759-770, https://doi.org/10.1007/s00484-014-0889-2.

_ A. J. E. Gallant, and N. J. Tapper, 2017: The sensitivity of urban meteorology to soil moisture boundary conditions: A case study in Melbourne, Australia. J. Appl. Meteor. Climatol., 56, 2155-2172, https://doi.org/10.1175/JAMC-D-17-0007.1.

Janjić, Z. I., 1994: The step-mountain eta coordinate model: Further developments of the convection, viscous sublayer, and turbulence closure schemes. Mon. Wea. Rev., 122, 927 945, https://doi.org/10.1175/1520-0493(1994)122<0927: TSMECM $>2.0 . \mathrm{CO} ; 2$.

Jones, D., W. Wang, and R. Fawcett, 2009: High-quality spatial climate data-sets for Australia. Aust. Meteor. Oceanogr. J., $\mathbf{5 8}$, 233-248, https://doi.org/10.22499/2.5804.003.

Kain, J. S., 2004: The Kain-Fritsch convective parameterization: An update. J. Appl. Meteor., 43, 170-181, https://doi.org/ 10.1175/1520-0450(2004)043<0170:TKCPAU > 2.0.CO;2.

Kala, J., J. P. Evans, and A. J. Pitman, 2015: Influence of antecedent soil moisture conditions on the synoptic meteorology of the Black Saturday bushfire event in southeast Australia. Quart. J. Roy. Meteor. Soc., 141, 3118-3129, https://doi.org/ 10.1002/qj.2596.

Kalkstein, L. S., D. Sailor, K. Shickman, S. Sheridan, and J. Vanos, 2013: Assessing the health impacts of urban heat island reduction strategies in the District of Columbia. Global Cool Cities Alliance Rep., 28 pp., https://www.coolrooftoolkit.org/ wp-content/uploads/2013/10/DC-Heat-Mortality-Study-forDDOE-FINAL.pdf.

Kohler, M., C. Tannier, N. Blond, R. Aguejdad, and A. Clappier, 2017: Impacts of several urban-sprawl countermeasures on building (space heating) energy demands and urban heat island intensities. A case study. Urban Climate, 19, 92-121, https://doi.org/10.1016/j.uclim.2016.12.006.

Kusaka, H., H. Kondo, Y. Kikegawa, and F. Kimura, 2001: A simple single-layer urban canopy model for atmospheric models: Comparison with multi-layer and slab models. 
Bound.-Layer Meteor., 101, 329-358, https://doi.org/10.1023/ A:1019207923078.

Li, D., and E. Bou-Zeid, 2013: Synergistic interactions between urban heat islands and heat waves: The impact in cities is larger than the sum of its parts. J. Appl. Meteor. Climatol., 52, 2051-2064, https://doi.org/10.1175/JAMC-D-13-02.1.

$\longrightarrow$, and _ 2014: Quality and sensitivity of high-resolution numerical simulation of urban heat islands. Environ. Res. Lett., 9, 055001, 10.1088/1748-9326/9/5/055001.

__ _ _ , and M. Oppenheimer, 2014: The effectiveness of cool and green roofs as urban heat island mitigation strategies. Environ. Res. Lett., 9, 055002, https://doi.org/ 10.1088/1748-9326/9/5/055002.

—, T. Sun, M. Liu, L. Yang, L. Wang, and Z. Gao, 2015: Contrasting responses of urban and rural surface energy budgets to heat waves explain synergies between urban heat islands and heat waves. Environ. Res. Lett., 10, 054009, https://doi.org/ 10.1088/1748-9326/10/5/054009.

Li, X. X., and L. K. Norford, 2016: Evaluation of cool roof and vegetations in mitigating urban heat island in a tropical city, Singapore. Urban Climate, 16, 59-74, https://doi.org/ 10.1016/j.uclim.2015.12.002.

Lim, K., and S. Hong, 2010: Development of an effective doublemoment cloud microphysics scheme with prognostic cloud condensation nuclei $(\mathrm{CCN})$ for weather and climate models. Mon. Wea. Rev., 138, 1587-1612, https://doi.org/10.1175/ 2009MWR2968.1.

Loughnan, M., N. J. Tapper, T. Phan, K. Lynch, and J. McInnes, 2013: A spatial vulnerability analysis of urban populations during extreme heat events in Australian capital cities. Monash University and National Climate Change Adaptation Research Facility Rep., 146 pp., https://www.nccarf.edu.au/business/sites/ www.nccarf.edu.au.business/files/attached_files_publications/ Loughnan-ExtremeHeatEventsinAustralianCapitalCitiesHighRes.pdf.

Ma, S., A. Pitman, M. Hart, J. P. Evans, N. Haghdadi, and I. MacGill, 2017: The impact of an urban canopy and anthropogenic heat fluxes on Sydney's climate. Int. J. Climatol., 37, 255-270, https://doi.org/10.1002/joc.5001.

- - J. Yang, C. Carouge, J. P. Evans, M. Hart, and D. Green, 2018: Evaluating the effectiveness of mitigation options on heat stress for Sydney, Australia. J. Appl. Meteor. Climatol., 57, 209220, https://doi.org/10.1175/JAMC-D-17-0061.1.

Miao, J. F., D. Chen, and K. Borne, 2007: Evaluation and comparison of Noah and Pleim-Xiu land surface models in MM5 using GÖTE2001 data: Spatial and temporal variations in near-surface air temperature. J. Appl. Meteor. Climatol., 46, 1587-1605, https://doi.org/10.1175/JAM2561.1.

Millstein, D., and S. Menon, 2011: Regional climate consequences of large-scale cool roof and photovoltaic array deployment. Environ. Res. Lett., 6, 034001, https://doi.org/ 10.1088/1748-9326/6/3/034001.

Mlawer, E. J., S. J. Taubman, P. D. Brown, M. J. Iacono, and S. A. Clough, 1997: Radiative transfer for inhomogeneous atmospheres: RRTM, a validated correlated $k$ model for the longwave. J. Geophys. Res., 102, 16 663-16 682, https://doi.org/ 10.1029/97JD00237.

Moore, C. E., and Coauthors, 2016: Reviews and syntheses: Australian vegetation phenology: New insights from satellite remote sensing and digital repeat photography. Biogeosciences, 13, 5085-5102, https://doi.org/10.5194/bg-13-5085-2016.

Morris, C. J. G., and I. Simmonds, 2000: Associations between varying magnitudes of the urban heat island and the synoptic climatology in Melbourne, Australia. Int. J. Climatol., 20, 1931-1954, https://doi.org/10.1002/1097-0088(200012)20: 15<1931::AID-JOC578>3.0.CO;2-D.

Nicholls, N., C. Skinner, M. Loughnan, and N. Tapper, 2008: A simple heat alert system for Melbourne, Australia. Int. J. Biometeor., 52, 375-384, https://doi.org/10.1007/s00484-007-0132-5.

Oke, T. R., 1987: Boundary Layer Climates. Routledge, 265 pp.

Papangelis, G., M. Tombrou, A. Dandou, and T. Kontos, 2012: An urban "green planning" approach utilizing the Weather Research and Forecasting (WRF) modeling system. A case study of Athens, Greece. Landscape Urban Plann., 105, 174-183, https://doi.org/10.1016/j.landurbplan.2011.12.014.

Perkins, S. E., and L. V. Alexander, 2013: On the measurement of heat waves. J. Climate, 26, 4500-4517, https://doi.org/10.1175/ JCLI-D-12-00383.1.

Pezza, A. B., P. van Rensch, and W. Cai, 2012: Severe heat waves in southern Australia: Synoptic climatology and large scale connections. Climate Dyn., 38, 209-224, https://doi.org/ 10.1007/s00382-011-1016-2.

Ramamurthy, P., D. Li, and E. Bou-Zeid, 2017: High-resolution simulation of heatwave events in New York City. Theor. Appl. Climatol., 128, 89-102, https://doi.org/10.1007/ s00704-015-1703-8.

Raupach, M. R., P. R. Briggs, V. Haverd, E. A. King, M. Paget, and C. M. Trudinger, 2009: Australian Water Availability Project (AWAP): CSIRO Marine and Atmospheric Research Component: Final Report for Phase 3. CAWCR Tech. Rep. 013, 72 pp, http://www.cawcr.gov.au/technical-reports/CTR_013.pdf.

Santamouris, M., 2014: Cooling the cities-A review of reflective and green roof mitigation technologies to fight heat island and improve comfort in urban environments. Sol. Energy, 103, 682-703, https://doi.org/10.1016/j.solener.2012.07.003.

Silva, H. R., P. E. Phelan, and J. S. Golden, 2010: Modeling effects of urban heat island mitigation strategies on heatrelated morbidity: A case study for Phoenix, Arizona, USA. Int. J. Biometeor., 54, 13-22, https://doi.org/10.1007/ s00484-009-0247-y.

Skamarock, W. C., and Coauthors, 2008: A description of the Advanced Research WRF version 3. NCAR Tech. Note NCAR/ TN-475+STR, 113 pp., http://dx.doi.org/10.5065/D68S4MVH.

Steadman, R. G., 1994: Norms of apparent temperature in Australia. Aust. Meteor. Mag., 43, 1-16.

Strahler, A., D. Muchoney, J. Borak, M. Friedl, S. Gopal, E. Lambin, and A. Moody, 1999: MODIS land cover and landcover change. MODIS Land Cover Product Algorithm Theoretical Basis Doc., version 5.0, 72 pp., http://modis.gsfc.nasa. gov/data/atbd/atbd_mod12.pdf.

Synnefa, A., A. Dandou, M. Santamouris, M. Tombrou, and N. Soulakellis, 2008: On the use of cool materials as a heat island mitigation strategy. J. Appl. Meteor. Climatol., 47, 28462856, https://doi.org/10.1175/2008JAMC1830.1.

Tewari, M., and Coauthors, 2004: Implementation and verification of the unified Noah land surface model in the WRF Model. 20th Conf. on Weather Analysis and Forecasting/ 16th Conf. on Numerical Weather Prediction, Seattle, WA, Amer. Meteor. Soc., 14.2A, https://ams.confex.com/ams/ 84Annual/webprogram/Paper69061.html.

Trewin, B., 2013: A daily homogenized temperature data set for Australia. Int. J. Climatol., 33, 1510-1529, https://doi.org/ 10.1002/joc.3530.

Troccoli, A., K. Muller, P. Coppin, R. Davy, C. Russell, and A. L. Hirsch, 2012: Long-term wind speed trends over Australia. J. Climate, 25, 170-183, https://doi.org/10.1175/2011JCLI4198.1. 
Upmanis, H., I. Eliasson, and S. Lindqvist, 1998: The influence of green areas on nocturnal temperatures in a high latitude city (Goteborg, Sweden). Int. J. Climatol., 18, 681-700, https://doi.org/10.1002/ (SICI)1097-0088(199805)18:6<681::AID-JOC289>3.0.CO;2-L.

Victorian Department of Health, 2009: January 2009 heatwave in Victoria: An assessment of health impacts. State of Victoria Rep., 24 pp., https://www2.health.vic.gov.au/Api/downloadmedia/ \%7B959CCD3C-8285-4938-872E-62E15AA62C62\%7D.

Wang, Z. H., E. Bou-Zeid, and J. A. Smith, 2013: A coupled energy transport and hydrological model for urban canopies evaluated using a wireless sensor network. Quart. J. Roy. Meteor. Soc., 139, 1643-1657, https://doi.org/10.1002/qj.2032.

S. K. Au, and J. A. Smith, 2011: Analyzing the sensitivity of WRF's single-layer urban canopy model to parameter uncertainty using advanced Monte Carlo simulation. J. Appl. Meteor. Climatol., 50, 1795-1814, https://doi.org/10.1175/ 2011JAMC2685.1.

Williams, S., M. Nitschke, T. Sullivan, G. R. Tucker, P. Weinstein, D. L. Pisaniello, K. A. Parton, and P. Bi, 2012: Heat and health in Adelaide, South Australia: Assessment of heat thresholds and temperature relationships. Sci. Total Environ., 414, 126133, https://doi.org/10.1016/j.scitotenv.2011.11.038.

Wu, J., Y. Zhou, Y. Gao, J. S. Fu, B. A. Johnson, C. Huang, and Y.-M. Kim, 2014: Estimation and uncertainty analysis of impacts of future heat waves on mortality in the eastern United States. Environ Health Perspect., 122, 10-16, https://doi.org/10.1289/ehp.1306670.

Yang, J., Z. H. Wang, F. Chen, S. Miao, M. Tewari, J. A. Voogt, and S. Myint, 2015a: Enhancing hydrologic modelling in the coupled Weather Research and Forecasting-urban modelling system. Bound.-Layer Meteor., 155, 87-109, https://doi.org/ 10.1007/s10546-014-9991-6.

,$- \ldots$, and K. E. Kaloush, 2015b: Environmental impacts of reflective materials: Is high albedo a "silver bullet" for mitigating urban heat island? Renewable Sustainable Energy Rev., 47, 830-843, https://doi.org/10.1016/j.rser.2015.03.092.

Zinzi, M., and S. Agnoli, 2012: Cool and green roofs. An energy and comfort comparison between passive cooling and mitigation urban heat island techniques for residential buildings in the Mediterranean region. Energy Build., 55, 66-76, https:// doi.org/10.1016/j.enbuild.2011.09.024. 